Prepared in cooperation with the Delta Regional Monitoring Program

\title{
Designing a High-Frequency Nutrient and Biogeochemical Monitoring Network for the Sacramento-San Joaquin Delta, Northern California
}
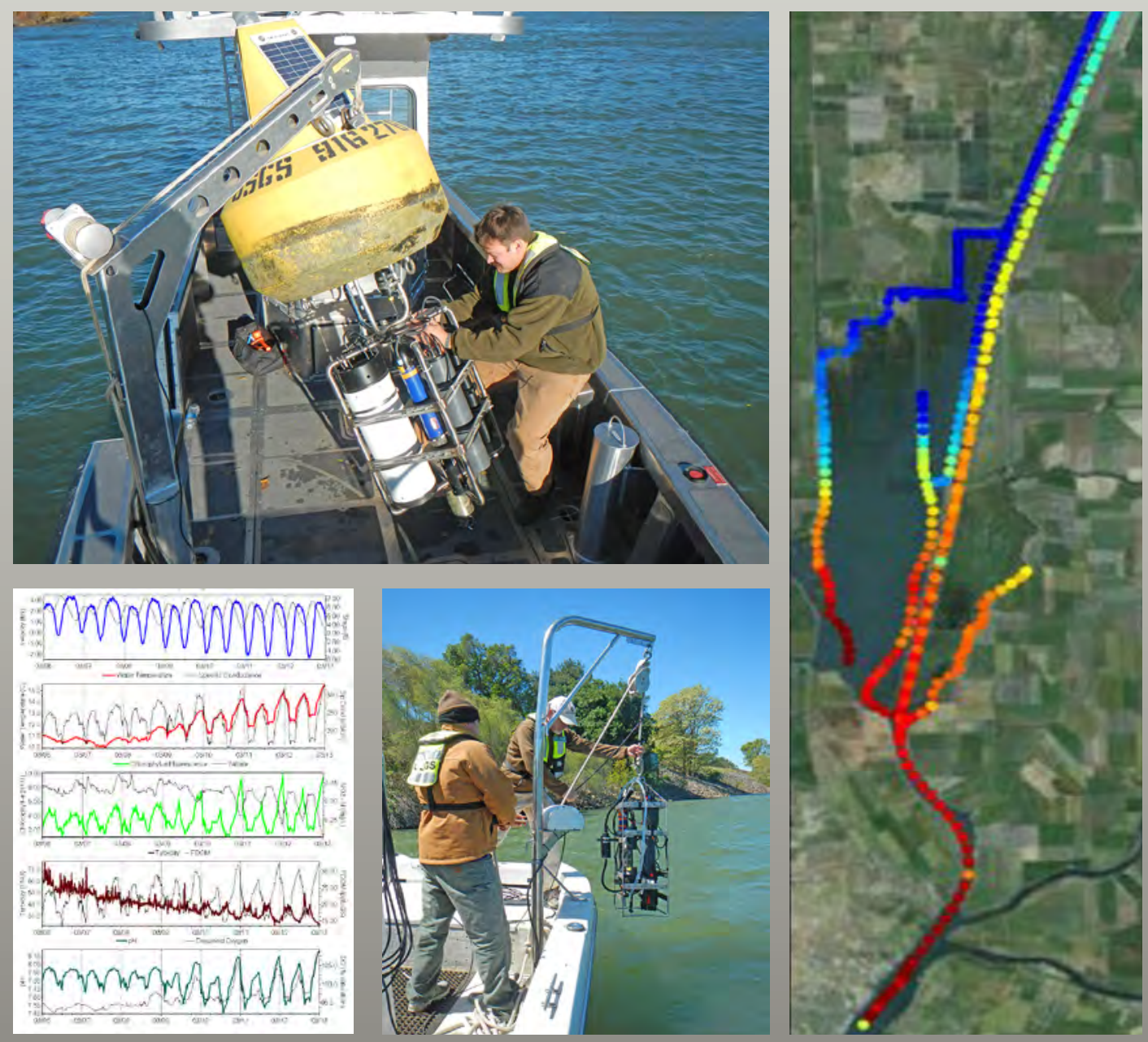

Scientific Investigations Report 2017-5058

U.S. Department of the Interior U.S. Geological Survey 


\section{FRONT COVER:}

Top left: Photograph showing monitoring buoy at Liberty Island, California, being serviced by hydrologic technician. Photograph by Bryan Downing, December 19, 2013.

Bottom Left: Example of a daily report for the monitoring buoy in Liberty Island, California that is emailed out to interested parties. Report generated by Frank Anderson, 2014.

Bottom middle: Photograph showing vertical water quality profiler in the Sacramento River.

Photograph by Michael Sauer, April 16, 2013.

Right: Map of nitrate concentrations collected via high speed boat mapping in the Cache Slough Complex/North Delta.

Map created by Travis von Dessonneck and Bryan Downing, October 10, 2014.

\section{BACK COVER:}

Top left: Photograph showing monitoring buoy at Liberty Island, California. Photograph by Bryan Downing, March 8, 2017.

Bottom Left: Photograph showing vertical profiling instrumentation, Sacramento River, Freeport, California. Photograph courtesy of Michael Sauer, April 16, 2013.

Right: Photograph showing flow monitoring station in Liberty Island, California.

Photograph by Bryan Downing, March 8, 2017.

Bottom: Photograph showing sunset in the northern Delta, Little Holland Tract, California.

Photograph by Bryan Downing, March 8, 2017. 


\section{Designing a High-Frequency Nutrient and Biogeochemical Monitoring Network for the Sacramento-San Joaquin Delta, Northern California}

By Brian A. Bergamaschi, Bryan D. Downing, Tamara E.C. Kraus, and Brian A. Pellerin

Prepared in cooperation with the Delta Regional Monitoring Program

Scientific Investigations Report 2017-5058 


\title{
U.S. Department of the Interior \\ RYAN K. ZINKE, Secretary
}

\section{U.S. Geological Survey William H. Werkheiser, Acting Director}

\author{
U.S. Geological Survey, Reston, Virginia: 2017
}

For more information on the USGS - the Federal source for science about the Earth, its natural and living resources, natural hazards, and the environment-visit https://www.usgs.gov or call 1-888-ASK-USGS.

For an overview of USGS information products, including maps, imagery, and publications, visit https://store.usgs.gov.

Any use of trade, firm, or product names is for descriptive purposes only and does not imply endorsement by the U.S. Government.

Although this information product, for the most part, is in the public domain, it also may contain copyrighted materials as noted in the text. Permission to reproduce copyrighted items must be secured from the copyright owner.

Suggested citation:

Bergamaschi, B.A., Downing, B.D., Kraus, T.E.C., and Pellerin, B.A., 2017, Designing a high-frequency nutrient and biogeochemical monitoring network for the Sacramento-San Joaquin Delta, northern California: U.S. Geological Survey Scientific Investigations Report 2017-5058, 40 p., https://doi.org/10.3133/sir20175058.

ISSN 2328-0328 (online) 


\section{Contents}

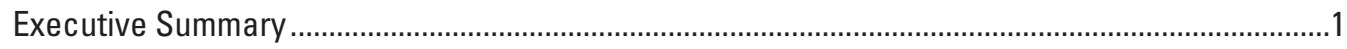

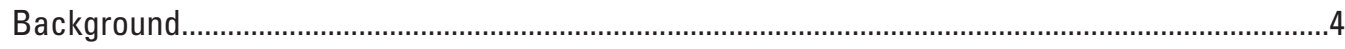

The Need For High-Frequency Monitoring Data ..................................................................

Existing Challenges to High-Frequency Nutrient Monitoring in the Delta ..............................6

Developing Monitoring Program Objectives and Design............................................................7

Monitoring Program Type 1-Concentrations, Fluxes, and Loads .........................................

Monitoring Program Type 2-Internal Sources, Processes, and Rates .................................

Monitoring Program Type 3-Ecosystem Level Effects.....................................................10

Designing a High-Frequency Monitoring Network .....................................................................11

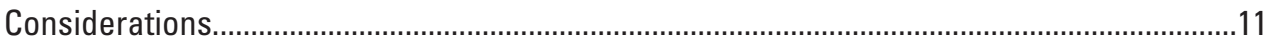

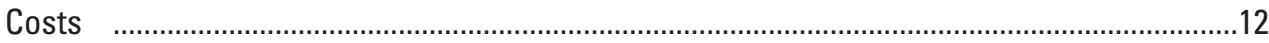

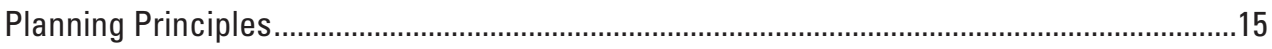

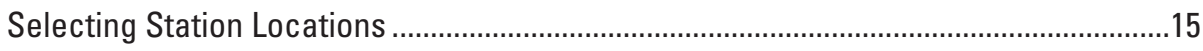

Station Attributes .....................................................................................................16

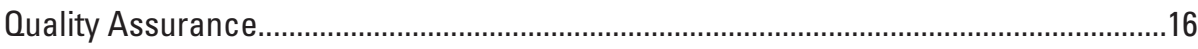

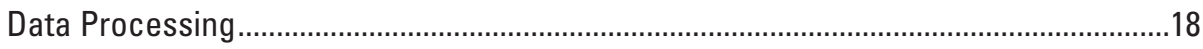

Example Network Plans........................................................................................................18

High-Frequency Monitoring Network Example 1-A Minimal Network Focused on Concentrations and Loads ...............................................................................19

High-Frequency Monitoring Network Example 2-A Network Focused on Internal Sources, Processes, and Rates..........................................................................21

High-Frequency Monitoring Network Example 3-A Comprehensive Network

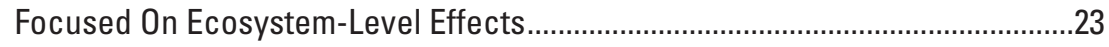

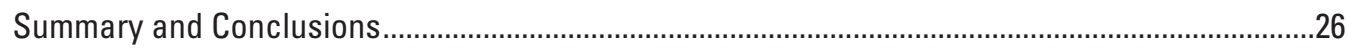

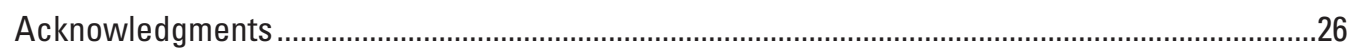

References Cited.............................................................................................................26

Appendix A. All Known High-Frequency Monitoring Stations and Water-Data Parameters Recorded, Sacramento- San Joaquin Delta, Northern California .......................................29 


\section{Figures}

1. Map showing Sacramento-San Joaquin Delta, northern California

2. Map of existing and proposed flow-monitoring stations, selected pumping stations, and selected wastewater treatment plants (WWTPs) in the Sacramento-San Joaquin Delta, northern California

3. Map showing three nutrients monitoring stations proposed as part of high-frequency Monitoring Network Example 1 in relation to existing and proposed flow-monitoring stations in the Sacramento-San Joaquin Delta, northern California...20

4. Map showing six nutrients monitoring stations proposed as part of high-frequency Monitoring Network Example 2 in relation to existing and proposed flow-monitoring stations in the Sacramento-San Joaquin Delta, northern California .....

5. Map showing 18 stations proposed as part of high-frequency Monitoring Network Example 3 in relation to existing and proposed flow-monitoring stations in the Sacramento-San Joaquin Delta, northern California

\section{Tables}

1. Initial assessment questions developed by the Delta Regional Monitoring Program. ....8

2. Detailed estimated 2015 costs of establishing and operating over a 1-year period multiparameter continuous monitoring stations including nitrate and ancillary parameters.

3. Detailed estimated daily 2015 costs for high-frequency mapping of water quality ........15

4. Three stations proposed as part of high-frequency Monitoring Network Example 1, Sacramento-San Joaquin Delta, northern California

5. Estimated 2015 costs for high-frequency Monitoring Network Example 1, consisting of three stations, Sacramento-San Joaquin Delta, northern California.

6. Six stations proposed as part of high-frequency Monitoring Network Example 2, Sacramento-San Joaquin Delta, northern California

7. Estimated 2015 costs for high-frequency Monitoring Network Example 2, consisting of six stations, Sacramento-San Joaquin Delta, northern California.

8. Eighteen stations proposed as part of high-frequency Monitoring Network Example 3, Sacramento-San Joaquin Delta, northern California

9. Estimated 2015 costs for high-frequency Monitoring Network Example 3, consisting of 18 high-frequency monitoring stations, Sacramento-San Joaquin Delta, northern California 


\section{Conversion Factors}

Inch/Pound to International System of Units

\begin{tabular}{lcl}
\hline Multiply & By & \multicolumn{1}{c}{ To obtain } \\
\hline & Area & \\
\hline square mile $\left(\mathrm{mi}^{2}\right)$ & 259.0 & hectare $($ ha) \\
square mile $\left(\mathrm{mi}^{2}\right)$ & 2.590 & square kilometer $\left(\mathrm{km}^{2}\right)$ \\
\hline
\end{tabular}

International System of Units to Inch/Pound

\begin{tabular}{lcl}
\hline \multicolumn{1}{c}{ Multiply } & By & To obtain \\
\hline kilometer $(\mathrm{km})$ & Length & mile (mi) \\
\hline \multicolumn{2}{c}{0.6214} & \\
\hline hectare (ha) & Area & acre \\
square kilometer $\left(\mathrm{km}^{2}\right)$ & 2.471 & acre \\
square kilometer $\left(\mathrm{km}^{2}\right)$ & 247.1 & square mile $\left(\mathrm{mi}^{2}\right)$ \\
\hline
\end{tabular}

\section{Datum}

Horizontal coordinate information is referenced to the North American Datum of 1983 (NAD 83).

\section{Abbreviations}

$\begin{array}{ll}\text { BMPs } & \text { best management practices } \\ \text { Delta } & \text { Sacramento-San Joaquin Delta } \\ \text { Delta RMP } & \text { Delta Regional Monitoring Program } \\ \text { DON } & \text { dissolved organic nitrogen } \\ \text { DOP } & \text { dissolved organic phosphorus } \\ \text { fDOM } & \text { fluorescent dissolved organic matter } \\ \mathrm{HF} & \text { high-frequency } \\ \mathrm{N} & \text { nitrogen } \\ \mathrm{NH}_{4} & \text { ammonium } \\ \mathrm{NO}_{3} & \text { nitrate } \\ \mathrm{P} & \text { phosphorus } \\ \text { TMDLs } & \text { total maximum daily loads } \\ \text { USGS } & \text { U.S. Geological Survey } \\ \text { WWTP } & \text { wastewater treatment plant }\end{array}$





\title{
Designing a High-Frequency Nutrient and Biogeochemical Monitoring Network for the Sacramento-San Joaquin Delta, Northern California
}

\author{
By Brian A. Bergamaschi, Bryan D. Downing, Tamara E.C. Kraus, and Brian A. Pellerin
}

\section{Executive Summary}

This report is the third in a series of three reports that provide information about how high-frequency (HF) nutrient monitoring may be used to assess nutrient inputs and dynamics in the Sacramento-San Joaquin Delta, California (Delta). The purpose of this report is to provide the background, principles, and considerations for designing an HF nutrient-monitoring network for the Delta to address high-priority, nutrient-management questions. The report starts with discussion of the high-priority management questions to be addressed, continues through discussion of the questions and considerations that place demands and constraints on network design, discusses the principles applicable to network design, and concludes with the presentation of three example nutrient-monitoring network designs for the Delta. For three example network designs, we assess how they would address high-priority questions that have been identified by the Delta Regional Monitoring Program (Delta Regional Monitoring Program Technical Advisory Committee, 2015).

This report, along with the other two reports of this series (Kraus and others, 2017; Downing and others, 2017), was drafted in cooperation with the Delta Regional Monitoring Program to help scientists, managers, and planners understand how HF data improve our understanding of nutrient sources and sinks, drivers, and effects in the Delta. The first report in the series (Kraus and others, 2017) provides an introduction to the reasons for and fundamental concepts behind using HF monitoring measurements, including a brief summary of nutrient status and trends in the Delta and an extensive literature review showing how and where other research and monitoring programs have used HF monitoring to improve our understanding of nutrient cycling. The report covers the various technologies available for HF nutrient monitoring and presents the different ways HF monitoring instrumentation may be used for both fixed station and spatial assessments. Finally, it presents numerous examples of how HF measurements are currently (2017) being used in the Delta to examine how nutrients and nutrient cycling are related to aquatic habitat conditions.

The second report in the series (Downing and others, 2017) summarizes information about HF nutrient and associated biogeochemical monitoring in the north Delta. The report synthesizes data available from the nutrient and water quality monitoring network currently (2017) operated by the U.S. Geological Survey in this ecologically important region of the Delta. In the report, we present and discuss the available data at various timescales - first at the monthly, seasonal, and inter-annual timescales; and, second, for comparison, at the tidal and event timescales. As expected, we determined that there is substantial variability in nitrate concentrations at short timescales, such as within a few hours, but also significant variability at longer timescales such as months or years. This high variability affects calculation of fluxes and loads, indicating that HF monitoring is necessary for understanding and assessing flux-based processes and outcomes in Delta tidal environments. 


\section{An Introduction to the Sacramento- San Joaquin Delta}

The Sacramento-San Joaquin Delta (Delta) of northern California is a tidal-freshwater river delta comprising about $3,000 \mathrm{~km}^{2}\left(1,158 \mathrm{mi}^{2}\right)$ of the northeastern extent of the San Francisco Estuary (fig. 1). Previously an area dominated by wetlands, the Delta has experienced large-scale alterations to aquatic habitats. Today, the area is a mosaic of deeply subsided islands predominantly maintained as agricultural, protected by more than $1,000 \mathrm{~km}$ of levees, and interconnected by an artificial network of deep tidal channels. Freshwater enters the Delta primarily from the Sacramento River to the north, the San Joaquin River to the south, and several other minor tributaries. Flows from these sources depend on seasonal precipitation, upstream reservoir releases, and discharges from agricultural and urban uses. The complex hydrodynamics that result from tidal and river currents propagating through the channel network affect all aquatic processes in the Delta because it alters residence times, causes high levels of mixing, and transports material both landward and seaward. Adding to this complexity is the export of water from the southern Delta by means of State and Federal water projects, which imposes a net northto-south flow through the Delta during periods of high pumping. It is estimated that the Delta supplies freshwater to more than 1 million ha of agricultural land and more than 27 million people (Delta Stewardship Council, 2016). The Delta also serves as critical habitat for fish, birds, and wildlife, but with ever-growing urban and agricultural demands on this resource, there is an increasing need to understand drivers of ecosystem health, including the role of nutrients.

\section{Nutrients}

Nutrient loads delivered by the Sacramento and San Joaquin Rivers comprise the largest source of nutrients to the Delta, with municipal and agricultural discharge contributing the bulk of these nutrients (Kratzer and others, 2011). The loading to the Delta can vary rapidly over time in response to storms, seasonal changes in discharge, and other processes, and is also influenced by long-term trends in climate. Municipal wastewater accounts for about 25 percent of the total nitrogen loads and 20 percent of the total phosphorus loads to the Delta (Domagalski and Saleh, 2015; Saleh and Domagalski, 2015).

There are some ongoing trends in nutrient concentrations and loads. Annual mean nitrate concentration in the Sacramento River has been recently decreasing, but the flow-normalized annual load has remained relatively constant (Schlegel and Domagalski, 2015). Conversely, in the San Joaquin River, no recent decreases are evident in the annual mean nitrate concentrations and loads (Schlegel and Domagalski, 2015). Central Valley watersheds supply only a small fraction of ammonium, the other major form of inorganic nitrogen, to the Delta, with the Sacramento Regional Wastewater Treatment Plant accounting for 90 percent of the total ammonium load (Jassby, 2008). Watershed contributions to concentrations and loads of ammonium and total phosphorus have recently continued to modestly decrease (Schlegel and Domagalski, 2015).

Although there are few data, loading of nutrients within the Delta is thought to be relatively small and constant, arising primarily from Delta island drainage (Novick and others, 2015). However, biological and physical processes within the Delta cause temporal and spatial changes in nutrient concentrations. Uptake of nutrients by phytoplankton and vegetation, nitrification (the biological transformation of ammonium into nitrate), and denitrification (the biological transformation of nitrate to nitrogen gas) vary seasonally and spatially in the Delta and play important roles in determining the local concentration and distribution of nutrients (Foe and others, 2010; Parker and others, 2012; Novick and others, 2015). Phosphate, which primarily travels with sediment, is similarly variable (Morgan-King and Schoellhamer, 2013; Cornwell and others, 2014). Some studies suggest that nutrient forms and ratios affect Delta food webs by changing patterns of phytoplankton productivity and community composition (Glibert, 2010; Parker and others, 2012; Senn and Novick, 2014). Trends in nutrient concentrations in the Delta generally have been flat or decreasing since 1998, which is attributed to management source-control efforts as they run counter to the increasing population density and agricultural intensity in the Central Valley (Novick and others, 2015). The Delta is the largest source of nutrients to the San Francisco Estuary. 


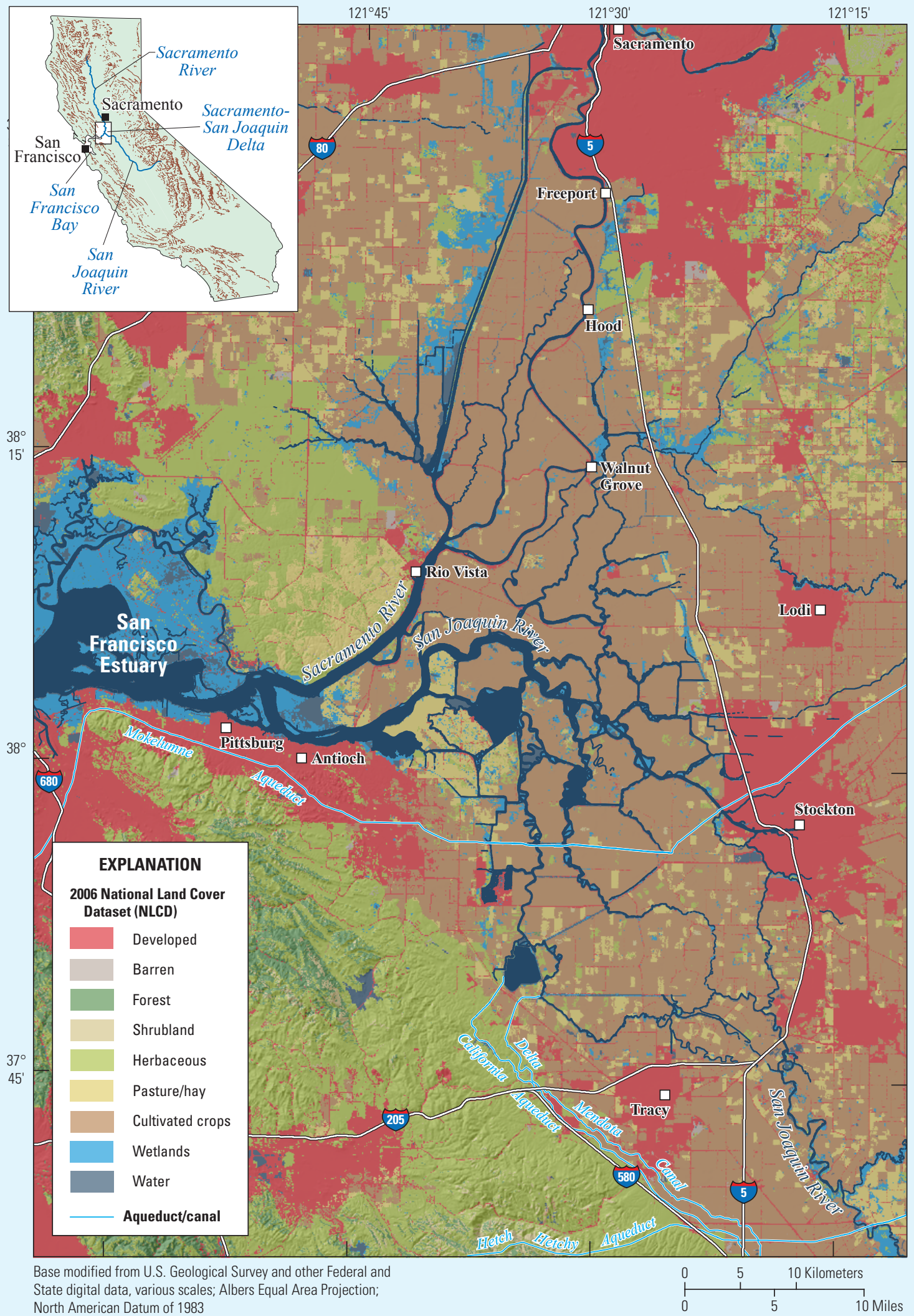

Figure 1. Sacramento-San Joaquin Delta, northern California. 


\section{Background}

\section{The Need For High-Frequency Monitoring Data}

In hydrologically complex tidal systems like the Sacramento-San Joaquin Delta (Delta), it is difficult to detect long-term trends in water quality because they occur against a background of short-term variability that can obscure the underlying change. Analyses of historical data from the Delta and elsewhere have shown that if high-frequency (HF) variability is not taken into account, trends observed in the degree (for example, concentration, discharge) and timing of any observed change, as well as values of any averaged quantities (for example, weekly, monthly, seasonal, and yearly averages typically used in regulatory frameworks) can be misleading (Schoellhamer and others, 2007; Pellerin and others, 2009). To accurately resolve any underlying change, sampling must occur often enough to capture the most rapidly varying component in the system. Sampling below this critical frequency can lead to errors in the assessment of the timing and magnitude of underlying trends, and also can completely miss important ephemeral events. As a consequence, many estuarine-monitoring programs in the San Francisco Estuary and elsewhere now record data continuously at 15 -minute intervals to resolve tidally forced variations and to ensure that short-term events are captured.

\section{Attributes of a High-Frequency, Nutrient Monitoring Network for the Delta}

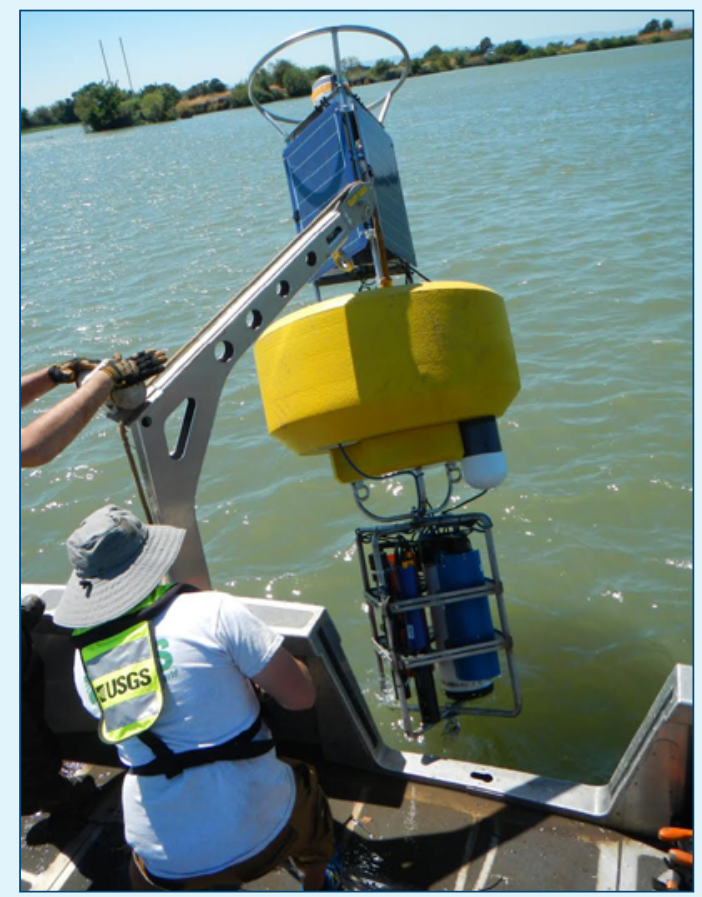

Deployment of monitoring buoy from which multiparameter water-quality sondes are suspended. Photograph by Bryan Downing, U.S. Geological Survey. September 9, 2014.
High frequency (HF): In tidal systems, measurements are made at least once every 15-20 minutes.

Continuous: Data are collected continuously over an extended period (months-years) of time.

Real time: Data are delivered to users in real time, facilitating decision making by managers, improving data quality, and acting as a trigger for additional data collection efforts. Data collected in the Delta are available at https://waterdata.usgs.gov/nwis.

Flux-based: Simultaneous collection of flow data permits calculation of mass fluxes and loads. Most existing nutrient stations in the Delta are co-located with the Delta flow-station network (Burau and others, 2016; https://doi.org/10.3133/ fs20153061).

Multi-parameter: Simultaneous collection of related water quality parameters improves understanding of nutrient sources, sinks, processing, and effects. In the Delta, stations that are equipped with nitrate sensors also measure temperature, $\mathrm{pH}$, conductivity, dissolved oxygen, turbidity, and fluorescence of dissolved organic matter, chlorophyll- $a$, and blue-green algae.

Network: Stations are spatially distributed so that sources, transport, and fate of nutrients can be tracked and their effects on Delta habitats can be assessed at multiple spatial scales. 
Estimating nutrient loading is a common component of most nutrient-monitoring programs. Most load estimates are based on discrete sampling programs that provide on the order of 5-50 discrete nutrient-concentration data points per year for a given location, combined with higher-frequency flow data. Empirically derived concentration-flow relationships typically are then used to quantify loads. Prior modeling of loads in different systems has indicated that HF monitoring can significantly improve quantification of river-borne nitrate loads, particularly at ecosystem-relevant timescales of weeks or months (Pellerin and others, 2009, 2014). Pellerin and others (2014) compared multiple methods for quantification of nitrate loads in the Mississippi River and found that although annual loads were comparatively similar between methods, daily, weekly, and monthly loads were considerably improved using HF data. Similarly, in an earlier study on the San Joaquin River, Pellerin and others (2009) found that conventional methods could overestimate or underestimate daily loads of nitrate by more than 25 percent in comparison to loads calculated from HF data. Thus, the use of HF monitoring is indicated, even for the relatively routine purpose of calculating external loads to the Delta (see section, "Attributes of a High-Frequency, Nutrient-Monitoring Network for the Delta").

Another common component of nutrient-monitoring programs is assessment of long- and short-term change. Whereas long-term monitoring data provide critical information to assess how water quality changes in relation to changes in land use, population growth, and climate, one of the great benefits of continuous, real-time HF data is the ability to analyze the effects of intentional and unintentional changes to a system. These effects may result from management actions such as implementation of new best management practices (BMPs), changes in reservoir releases or diversions, or emplacement of temporary barriers. They also may include unforeseen events such as levee failure, spills, or floods. Data from each event provide an opportunity to learn more about the function of Delta systems that is often lost because of logistical constraints when relying on traditional discrete sampling programs. Furthermore, we have learned that to improve understanding of nutrient sources, sinks, transformations, and effects, it is necessary for monitoring records to capture various events such as storms, floods, and reservoir releases. This approach yields more robust information than is possible by studying one or only a few such events (Saraceno and others, 2009; Pellerin and others, 2011). The only practical method for collection of such data is through an in situ, continuous monitoring network that collects data at appropriate spatial and temporal scales (Kraus and others, 2017). The goal of HF monitoring is not to replace sample-based monitoring such as that historically conducted in the Delta, but rather to augment those programs and to improve the quality and value of information available to managers.
Such an augmented monitoring network supports a better understanding of the separate and different effects that changing nutrient concentrations may have in different parts of the Delta. Nutrients will have different lifetimes within the Delta depending on, for example, hydrology (water velocity, temperature, residence time), benthic substrate, abundance of tidal wetlands, presence of submerged aquatic vegetation, and extent of agricultural diversion. Therefore, as inflows change because of natural variability, climate change, or management actions, an HF monitoring network can provide a clearer picture of the ecosystem response within the different biophysiographic regions of the Delta. Furthermore, these individual biophysiographic regions also are in a continuing process of change, characterized, for example, by restoration projects, changing agricultural practices, and continued subsidence.

In addition to collection of HF (15-minute) data at a fixed station, boat-based instrument platforms recently have been developed for collection of spatially explicit data across a broad region over a short period of time (Crawford and others, 2015; Fichot and others, 2016; Downing and others, 2017). "Mapping" allows for collection of data between established fixed stations to help resolve gradients in nutrient concentrations and other parameters. Furthermore, because the measurements can be made across different types of aquatic habitats (major channels, backwater sloughs, flooded islands, tidal wetlands), these data can help in identifying nutrient sources and hot spots of nutrient consumption or transformation, and in quantifying how nutrients vary in relation to other measured parameters. Mapping also can be used to verify whether fixed stations are adequately representing local conditions. Mapping is one part of an integrated nutrient-monitoring approach.

Although the focus here primarily is on nutrient monitoring, to address management and policy questions and to realize the greatest benefit from an investment in HF monitoring, every effort should be made to extract maximum knowledge and value by linking nutrient data to other data being collected in the system (for example, river flows, water temperature, dissolved oxygen, chlorophyll- $a$ concentration, clam abundances, fish populations, and treatment plant operations). In particular, efforts are underway to identify links between nutrients and aquatic primary productivity (a function of phytoplankton abundance, species composition, and health), the spread of invasive aquatic vegetation, the success of wetland restoration efforts, and the health of the pelagic food web. It also is becoming apparent that a more comprehensive system for monitoring beneficial and harmful algal blooms, and the conditions that cause them, is needed in the Delta and other estuarine systems (Graham, 2007; Lehman and others, 2013). As blooms are ephemeral events, continuous monitoring is necessary to assess whether their cause and frequency of occurrence, duration, or extent is changing. 
As HF monitoring data-from fixed stations and boat-based mapping campaigns_-become integrated into habitat evaluation models and into physicaldynamic models, the value, need for, and power of such data are expected to grow. In the near-term, improvements in data visualization and analysis can provide tools for more rapid assessments and greater recognition and anticipation of deleterious events. With sufficient continuous real-time HF data, modeling tools may be developed that integrate these data with real-time meteorological and hydrological data to forecast conditions in the Delta. As computational power continues to improve, continuous real-time models of physical and biogeochemical dynamics in the Delta can use realtime data to better understand within-Delta nutrient sources, sinks, transformations, and effects.

\section{Existing Challenges to High-Frequency Nutrient Monitoring in the Delta}

To fully understand the sources, sinks, transformations, and effects of nutrients on water quality and ecosystem function, we need to understand not only nutrient concentrations, fluxes, and loads, but also their specific forms and ratios. The nutrient forms have ramifications for their transport, persistence, biogeochemical cycling, and toxicity, which, in turn, determine their biological effects. For example, nitrate $\left(\mathrm{NO}_{3}\right)$ and ammonium $\left(\mathrm{NH}_{4}\right)$ may differentially affect phytoplankton primary production (for example, Glibert and others, 2014; Senn and Novick, 2014). The ratios of nutrients are another factor that should be taken into consideration, particularly nitrateto-ammonium ratios $\left(\mathrm{NO}_{3}: \mathrm{NH}_{4}\right)$ and nitrogen-tophosphorus ratios (N:P) of dissolved and particulate material (Conley and others, 2009; Senn and Novick, 2014; Paerl and Otten, 2016). Data from the Delta indicate that concentrations and ratios can change quickly (Kraus and others, 2017). Furthermore, whether nutrients are in the dissolved or particulate phase dictates how they will be transported through the system and their ecological role. Similarly, organic compared to inorganic forms of both $\mathrm{N}$ and $\mathrm{P}$ can have different effects on water quality and ecosystem function.

Instruments that can measure nutrients other than nitrate in situ and at appropriate frequencies are still in their developmental infancy, often with limited
There is widespread recognition that, in order to obtain information to support ecosystem management decisions and plan for future conditions, a monitoring program should not simply document the status and trends in constituent concentrations and loads, but should strategically collect information to inform a processesbased understanding of constituent sources, sinks, transformations, and effects, and thus allow improved forecasting of water quality and ecosystem health.

capabilities, particularly in regard to their deployment duration (Pellerin and others, 2016). Until further research and development work is completed, this challenge restricts the present-day use of such instruments in HF monitoring programs to targeted events and special studies. Phosphate analyzers that use wet chemistry followed by an optical measurement presently are in commercial production and can be deployed relatively routinely, but the costs and complexity of their operation and maintenance are still high. At present (2017), there are no commercially available sensors for in situ measurement of ammonium, although the U.S. Geological Survey (USGS) currently has two prototype ammonium sensors operating periodically in the Delta. Organic forms of nitrogen and phosphorus in the dissolved phase (dissolved organic nitrogen [DON] and dissolved organic phosphorus [DOP], respectively) can be assessed using their relationship to fluorescent dissolved organic matter (fDOM), which is easily measured in situ; however, empirical relationships between fDOM, DON, and DOP have yet to be developed for the Delta. Tools that not only measure turbidity, a proxy for sediment concentration, but also can identify and quantify organic particles, as differentiated from mineralic particulate material, also are under development. 


\section{Developing Monitoring Program Objectives and Design}

To design a successful HF nutrient-monitoring program for the Delta, the first requirement is a clear definition of the overarching monitoring program objectives, which starts with a clear understanding of how the data will be used and by whom. It also is important to understand how HF measurements fit into the larger water quality monitoring program and how HF measurements integrate with other components of the greater Delta Regional Monitoring Program (Delta RMP) and all other Delta monitoring activities such as those conducted under the auspices of the Interagency Ecological Program.

In the broadest terms, HF monitoring should provide timely, high-quality information to managers that permits them to more effectively manage the Delta as a functioning ecosystem and the primary water supply for much of California (DiGennaro and others, 2012). One of the needs of future monitoring programs in the Delta is to fill data gaps, improve understanding, and advance water quality forecasting models. To aid in the development of regional monitoring programs for the Delta, the Delta RMP developed a list of initial assessment questions (table 1). These questions relate not only to monitoring of nutrients in the Delta, but also to monitoring for mercury, pesticides, toxicity, and pathogens.

To illustrate how the objectives of a monitoring program influence its design, we divided the RMP initial assessment questions into three groups corresponding to types of monitoring programs, based roughly on the complexity of the resulting network design. Monitoring Program Type 1 focuses on quantifying nutrient fluxes and loads entering and exiting the Delta. Monitoring Program Type 2 focuses on identifying internal nutrient loads and key processes, and quantifying rates of nutrient transformation and loss in the Delta. The most ambitious monitoring program, Monitoring Program Type 3, focuses on identifying and understanding the effects of nutrients on other ecosystem components. The different program types have different challenges and use contrasting approaches, and ultimately place different requirements and constraints on the design of an HF nutrients monitoring system. Each program type also addresses a different group of the initial assessment questions identified by the Delta RMP (table 1).

\section{Monitoring Program Type 1-Concentrations, Fluxes, and Loads}

Accurate concentration measurements and associated estimates of loads entering and exiting a system are important to managers and regulators who want to identify and quantify nutrient sources, assess long-term trends, and identify ecosystem impacts. These data, for example, are used to

\section{Terminology—FLUX and LOAD}

FLUX: Constituent flux, sometimes referred to as instantaneous load, has units of mass per unit time. It is calculated as the product of concentration and discharge through a channel cross section; it typically is reported as the flux per second, but also can be reported per minute, hour, day, or other time period.

LOAD: Constituent load is calculated as the integrated flux over a specified period of time, and has units of mass. The time over which the flux is integrated must be specified. For example, an annual load is the flux integrated over a year, but other time periods may be chosen.

NOTE: As a general rule, the higher the temporal frequency (resolution) of the flux data, the more accurate the load calculation will be.

determine acceptable "total maximum daily loads" (TMDLs) required by the Clean Water Act (40 CFR) for impaired water bodies. Under this act, high-quality data are needed to determine water body impairment with regard to "beneficial uses" and to plan and implement management practices aimed at protecting or restoring beneficial uses and protecting human health.

A comparatively straightforward monitoring program focused on quantification of nutrient concentrations for the purpose of calculating constituent fluxes and loads in the Delta is likely to concentrate its efforts on measuring (1) nutrients entering and exiting the entire Delta, and (2) nutrient sources and sinks in specific regions of the Delta. This program type relates to initial assessment questions ST-1, ST-1B, SPLP-1B, and SPLP-1G (table 1). Nutrient fluxes - a rate defined as the mass of a constituent moving past a channel cross section per unit time (typically per second, minute, hour, or day) - are of key importance in the Delta where complex hydrodynamics mean fluxes can rapidly vary in magnitude and sign. For example, nutrients passing a station flowing seaward during ebb tide have a positive flux value, while nutrients passing that same station flowing landward during flood tide have a negative flux value. The ability to accurately calculate nutrient loads - defined as the flux of a constituent integrated over a specified period of time (most commonly over a year) - relies on the summation of accurate flux data. Thus, in addition to requiring nutrient concentration data, a monitoring program geared towards documenting fluxes and loads requires collection of accurate flow data for the site of interest. 
Table 1. Initial assessment questions developed by the Delta Regional Monitoring Program.

[Columns to the right indicate whether each question would be addressed by the three different plans presented in section, "Example Network Plans." Blank cells indicate questions not addressed by the example network scenario. For details, see Delta Regional Monitoring Program Technical Advisory Committee (2015)]

\begin{tabular}{|c|c|c|c|c|}
\hline \multirow{2}{*}{\multicolumn{2}{|c|}{ Delta RMP initial assessment questions }} & \multicolumn{3}{|c|}{ Example network \# } \\
\hline & & \multicolumn{3}{|c|}{ Question addressed } \\
\hline \multicolumn{5}{|c|}{ Status and trends (ST) } \\
\hline ST-1 & $\begin{array}{l}\text { How do concentrations of nutrients (and nutrient-associated parameters) } \\
\text { vary spatially and temporally? }\end{array}$ & & Yes & Yes \\
\hline ST-1B & $\begin{array}{l}\text { How are ambient levels and trends affected by variability in climate, } \\
\text { hydrology, and ecology? }\end{array}$ & Partially & Partially & Yes \\
\hline ST-1C & $\begin{array}{l}\text { Are there important data gaps associated with particular water bodies } \\
\text { within the Delta subregions? }\end{array}$ & & Partially & Yes \\
\hline ST-2 & What is the current status of the Delta ecosystem as influenced by nutrients? & & Yes & Yes \\
\hline \multicolumn{5}{|c|}{ Sources, pathways, loadings, and processes (SPLP) } \\
\hline SPLP-1 & $\begin{array}{l}\text { Which sources, pathways, and processes contribute most to observed } \\
\text { levels of nutrients? }\end{array}$ & & & Yes \\
\hline SPLP-1A & $\begin{array}{l}\text { How have nutrient or nutrient-related source controls and water management } \\
\text { actions changed ambient levels of nutrients and nutrient-associated parameters? }\end{array}$ & Partially & Partially & Yes \\
\hline SPLP-1B & What are the loads from tributaries to the Delta? & Yes & & Yes \\
\hline SPLP-1C & What are the sources and loads of nutrients within the Delta? & & Yes & Yes \\
\hline SPLP-1D & What role do internal sources play in influencing observed nutrient levels? & & & Yes \\
\hline SPLP-1E & Which factors in the Delta influence the effects of nutrients? & & Partially & Yes \\
\hline
\end{tabular}


Because most water enters the Delta from the Sacramento River (about 84 percent annually) and San Joaquin River (about 13 percent annually) (Jassby and Cloern, 2000), and exits the Delta through Suisun Bay, establishment of monitoring stations at the periphery of the Delta at approximately these three locations would allow a first approximation of nutrient loads entering and exiting the Delta. The Sacramento and San Joaquin Rivers both receive nutrients from natural, agricultural, and urban sources. In particular, large inputs of both $\mathrm{N}$ and $\mathrm{P}$ enter these rivers from wastewater treatment plant (WWTP) discharges-Sacramento Regional WWTP on the Sacramento River and the City of Stockton Regional Wastewater Control Facility on the San Joaquin River (Saleh and Domagalski, 2015). Whether a monitoring station is located upstream or downstream of these inputs will thus have an extremely large effect on calculated loads entering the Delta.

For example, Sacramento River nutrient load estimates based on data collected at Freeport (river mile 46.4, just upstream of the Sacramento Regional WWTP) do not include WWTP nutrient inputs, and thus, by default, consider those loads as internal to the Delta (for example, Kratzer and others, 2011; Schlegel and Domagalski, 2015). In contrast, they are included in Sacramento River loads calculated downstream of the WWTP discharge location at approximately river mile 44 (Station C3; Novick and others, 2015; Saleh and Domagalski, 2015). When deciding on the specific location of monitoring stations that will represent nutrient inputs to the Delta, it is important for managers to agree on whether they want to focus on a site representing the most upstream point of the legally defined Delta or a point farther downstream that might better meet the monitoring objectives.

Similarly, the decision to establish a HF monitoring site that will represent water exiting the Delta needs to consider whether inputs from Suisun Bay should be included or calculated separately. Historically, estimates have been made from stations located both upstream (USGS station D10) and downstream (USGS station D6) of Suisun Bay, but because of tidal action, both of these locations receive water that has interacted with the Suisun Bay ecosystem and both can even receive wastewater-derived nutrients from downstream sources. To add to this complexity, water exported from the Delta by State and Federal water projects to the south can remove a large portion of water and nutrients from the Delta (Novick and others, 2015).

Identification and quantification of more diffuse internal loads and sinks in specific regions of the Delta present yet another layer of complexity. Given that internal loads are contributed largely by ungaged and nonpoint sources (Novick and others, 2015), direct measurement of internal contributions must be calculated from the difference in concentration, load, or flux between two points along a Delta flow network.

\section{Nutrient Monitoring Program Objectives}

\author{
Program Type \#1 \\ Concentrations, Fluxes, and Loads \\ Program Type \#2 \\ Internal Sources, Processes, and Ratea \\ Program Type \#3 \\ Ecosystem Level Effects
}

An example of this can be found in O'Donnell (2014), where nitrate inputs to the Sacramento River between Freeport (river mile 46) and Walnut Grove (river mile 23) were calculated using the difference in HF nitrate concentration data between these two stations. This study is instructive because it highlights the difficulty in making such calculations in hydrodynamically complex environments, even given this relatively simple channelized section of the Sacramento River. Because this section of the river has tidally driven changes in water velocity, the time it takes for water to travel between these stations is highly variable. Therefore, a modeling approach was necessary to ensure data from both stations were appropriately matched such that they represented the same water parcel as it transited this river section. The model was validated by taking advantage of natural tracers of water movement recorded over a 1-year period of HF, continuous data collection at both stations. A similar approach would be necessary for assessing nutrient inputs in the central Delta, albeit the greater hydrologic complexity would increase the uncertainty of the calculated value.

\section{Monitoring Program Type 2-Internal Sources, Processes, and Rates}

A second type of monitoring program is focused on identification and quantification of within-Delta sources and processing that affect nutrient concentrations, fluxes, and loads. These processes may include microbial transformations (for example, mineralization, nitrification, and denitrification), abiotic transfer between water and sediment, biological uptake by phytoplankton and terrestrial vegetation, and burial by sedimentation of detrital material (Novick and others, 2015). A process-based objective relates to initial assessment questions ST-1, ST-1A, ST-1B, SPLP-1D, and SPLP-1F (table 1). This objective is more complex and, thus, more challenging to address than the objective of simply 
assessing nutrient concentrations, fluxes, and loads, placing greater demands on data generated by an HF monitoring network. With regard to nutrient monitoring, this approach is the same as that for estimating fluxes and loads described above under Program Type1 (simultaneous collection of HF nutrient concentration and flow data), but additional ancillary measurements are required and monitoring stations must be spatially arrayed to capture the relevant processes in the complex hydrodynamics of the region. Measured changes between stations in concentrations, flux, or loads must be apportioned to a corresponding source or sink. For example, ammonium loss could be due to (1) uptake by phytoplankton as evidenced by increases in chlorophyll- $a$, dissolved oxygen, and $\mathrm{pH}$ (the latter two parameters are related to photosynthetic rate), (2) nitrification (conversion of ammonium to nitrate), or (3) both (1) and (2). A type-2 program uses simultaneous HF measurements of nitrate, ammonium, chlorophyll- $a$, dissolved oxygen, $\mathrm{pH}$, water flow, and other parameters to quantify these different processes.

Because processes and rates also are determined by environmental drivers such as temperature, $\mathrm{pH}$, salinity, light, and hydrodynamics, collection of these kinds of ancillary data often is a required component of a process-based monitoring program. Furthermore, because residence time is a master variable determining the extent to which a process can occur, connecting water quality data to information about water residence time (that is, the time it takes water to move through a specific region of the Delta) enhances our ability to identify processes affecting nutrient concentrations, ratios, and forms, and to accurately determine their rates.

\section{Monitoring Program Type 3-Ecosystem Level Effects}

The third type of HF nutrient-monitoring program is the most ambitious and produces the richest information. It is intended to help elucidate how an ecosystem is affected by nutrients, how management actions affect nutrient sources and cycling, and how water quality conditions will change in the future in response to system modifications such as wetland restorations, droughts, climate change, and population changes. These objectives relate to or incidentally address most of the initial assessment questions (table 1), and differ from the other two monitoring programs in that they require not only collection of ancillary data pertaining to water quality, flow, and environmental drivers, but also collection of robust data relating to the effect of interest. Thus, with this larger scope in mind, the monitoring of nutrients needs to take place within the framework of other monitoring efforts taking place in the Delta. Current high-priority topics, to name a few, include:
- Location, extent, biomass, and type of invasive aquatic vegetation;

- Location, abundance, timing, duration, and frequency of both beneficial and harmful algal blooms;

- Extent, species composition, and productivity of wetland vegetation; and

- Population characteristics of threatened and endangered fish taxa.

The initial assessment questions in table 1 are designed to support adaptive management. For example, whereas nutrient availability is expected to affect the success of wetland restoration projects, the establishment of these habitats, in turn, is expected to affect nutrient concentrations by increasing nutrient demand, altering process rates, and changing water residence time (Downing and others, 2016), affecting nutrient concentrations, forms, and ratios. Similarly, the adoption of best management practices can alter nutrient loads to the Delta, but without collection of appropriate data to analyze long-term trends, managers cannot know if these practices are actually helping to meet water quality objectives (Schlegel and Domagalski, 2015). Tracking nutrients in the Delta under existing and future conditions is particularly relevant in the Delta considering forthcoming (2019-23) changes to the Sacramento Regional WWTP, which will include conversion to biological nitrification and denitrification treatments. The upgrade is expected to decrease WWTP-derived nitrogen inputs to the Sacramento River by more than 65 percent, while shifting the dominant form of nitrogen in effluent from ammonium to nitrate (O’Donnell, 2014; Kraus and others, 2017).

The need for answers to ecosystem level questions makes clear the benefits of and need for integrating HF monitoring into a comprehensive, directed, regional research and modeling program. In the context of directed research, HF monitoring can provide the information necessary to develop, calibrate, and validate the complex hydrodynamicbiogeochemical models needed to make such assessments. Without HF measurements, such models must rely on the small number of published values extrapolated from other systems (for example, for rates of uptake, transformation, or loss under different environmental conditions of temperature, light, etc.). Recent examples of how HF measurements in the Delta support the determination of nutrient transformation rates and exchanges between different environmental pools include rates of net ecosystem $\mathrm{N}$ uptake (Downing and others, 2016), and determination of nitrification rates (O'Donnell, 2014). Futher examples are given in the first report of this series (Kraus and others, 2017). 


\section{Designing a High-Frequency Monitoring Network}

This section is intended to provide guidance for translating the goals and objectives of an HF monitoring network into a functional plan. The section is divided into (1) the considerations that should be applied during the planning process to further refine the scope and purpose of the network in a way that informs the network design, (2) the approximate 2015 costs for station infrastructure, installation, instrumentation, operation, and maintenance to help match available resources to initial and ongoing expenses, and (3) the operational principles and constraints that should be applied to designing the network. The following section provides examples of how these considerations, principles, and costs are put to use in the design and planning process.

\section{Considerations}

As discussed above, prior to establishing an HF monitoring program in the Delta, the goals and objectives of the monitoring effort should be clearly identified and the purposes for which the data will be used should be clearly defined. Further refinement of the goals and objectives typically is required prior to design of the network to match the scope of the design with available human and monetary resources and to ensure that the network design is suitable for monitoring at the desired level of accuracy, temporal resolution, and spatial resolution. Given that network design typically is a tradeoff between competing resources and objectives, defining the objectives in detailed terms helps assess whether a network design will be able to meet the monitoring objectives. Every possible effort should be made to use existing stations (appendix A). Examples of the types of questions that should be answered to start planning a monitoring network are as follows:

- What level of accuracy is needed for quantification of inputs of nutrients from (A) upstream of the Delta, and (B) internal sources within the Delta to meet the objectives of the network? What specific information is needed (for example, nutrient concentrations, forms, fluxes, and loads; flow measurements; and ancillary data)? What is the temporal resolution neededhourly, daily, monthly, or annually? How accurate does each specific type of information need to be at each timescale?

- What spatial resolution is required to meet the objectives of the network? What is the spatial extent of the network?
- How will high-resolution mapping be useful for filling in gaps in the network? At what frequency and spatial extent should map data be collected?

- Will the focus be only on nutrient loads and fluxes, or is the network intended to provide information about the effects of nutrients on the ecosystem?

- How important are estimates of transformation rates (due to, for example, uptake, denitrification, and particle settling)? What level of accuracy is needed in the determination of these rates? Is there a need to explore spatial variability in these rates?

- How important are assessments of distant effects? Will the data from the network be used to assess propagation or effects of nutrients contributed by point sources to locations distant from the source? Which point sources? Over what spatial domain will effects be evaluated?

-Will the network act as an "early warning system" of deleterious or beneficial conditions? What types of conditions? What are the response thresholds?

- Will data from the network be used to trigger additional monitoring activity such as to sample a phytoplankton or harmful algal bloom or low-dissolved oxygen event?

- Will the data be used as input to specific modeling efforts? What constituents are needed, and with what accuracy and frequency?

- How will the data be made available to users?

- What funding is available?

- What agencies will be involved in operation of the network, and what will be their respective roles?

\section{- What future needs are anticipated?}

Consideration should be given to the fact that HF in situ measurements are not practical, or warranted, in every location. Because of technological limitations, it also is not yet possible to collect in situ HF data for all desired parameters (for example, ammonium). For some parameters, short-term instrument deployments or collection of grab samples and analysis by traditional methods will be required. Furthermore, some sites may not be amenable to continuous monitoring because site conditions preclude the possibility of using existing instrumentation. For example, excessively high turbidity can interfere with measurements made by optical instruments (Downing and others, 2012; Pellerin and others, 2013). Some sites may be subject to such extensive biofouling so as to make continuous measurements impractical. 
It may be prudent to identify which users beyond the nutrient-monitoring program will find the data from the monitoring network useful. A broad base of users likely will make support of the network more sustainable. For example, much of the data produced by the nutrient-monitoring network would be directly applicable to the evaluation of drinking water quality with respect to dissolved organic carbon concentration and bromide, both of which are problematic in the context of drinking water treatment. Elevated nutrients also contribute to downstream aquatic production, particularly when waters exported from the Delta clarify in storage reservoirs, and the resulting phytoplankton increases the amount of dissolved organic carbon, and also can contribute to taste and odor problems (Kraus and others, 2008; Carpenter and others, 2013). The data from a nutrients network also may be useful for identifying the sources and effects of contaminants like mercury (Bergamaschi and others, 2012).

Because it is unlikely that a network will be established with sufficient spatial resolution to resolve the entire Delta, and because a fixed station network usually locates sites in high-capacity channels to facilitate flux calculations, part of the program is likely to include a systematic mapping element to periodically assess conditions not well represented by the fixed station network (Kraus and others, 2017).

\section{Costs}

Initial installation costs of an HF monitoring network can be large, due primarily to initial investments in instrumentation. However, because of advances in technology and automation, the operation of an HF nutrient-monitoring network over the long term is not necessarily more expensive than the traditional monthly or twice-monthly sampling followed by laboratory sample analysis. Moreover, costs must be weighed against the scientific value of the data obtained from such a network, the management (including scientific management) value of obtaining the data in real time, and the cost of obtaining the necessary information using discrete grab sampling. Costs also should be evaluated within the framework of other investments, such as management actions, modeling efforts, and investment in infrastructure. A cost-benefit analysis of HF data collection, therefore, should consider the value of this approach compared to other data collection approaches. For example, HF data can:

- Provide improved characterization of source contributions,

- Provide more accurate load estimates,

- Reliably capture event-related changes in concentration,

- Provide real-time data to inform immediate management actions, and
- Provide other scientific benefits (summarized in section, "Background") that improve assessment of the efficacy of nutrient-management programs.

These benefits must be weighed against the costs of alternative schemes such as using automated samplers or high-intensity grab sampling programs, as well as the "costs" (various possible types, including monetary) of high error in load estimates, poor resolution, and source misattribution. Costs also should be evaluated within the framework of other investments, such as management actions, modeling efforts, and investment in infrastructure.

The estimated 2015 costs associated with installation and maintenance of a single, HF nutrient-monitoring station are summarized in table 2, including the costs of instrumentation and infrastructure procurement, installation, annual operations, annual maintenance, and data management and analysis. These costs are based on the existing USGS California Water Science Center HF water quality monitoring network, which operates stations equipped to measure nitrate, temperature, conductivity, $\mathrm{pH}$, dissolved oxygen, turbidity, chlorophyll- $a$, phycocyanin (a tracer for blue-green algae such as Microcystis), and fluorescent dissolved organic matter (fDOM, a proxy for dissolved organic carbon concentration) (Downing and others, 2017). Flow data are collected separately (Burau and others, 2016). Costs also are shown for HF water quality mapping (table 3).

HF monitoring involves an initial investment of about $\$ 150,000$ per station (including instrument purchases, installation costs, and institutional overhead) and an ongoing cost of about $\$ 127,000$ per year (including annual operations, maintenance, instrument replacement, data management, data analysis, and institutional overhead). These costs assume each station will be serviced approximately monthly, and that discrete samples will be collected to verify and calibrate the sensor data.

In comparison to these HF costs, collecting a single discrete grab sample was estimated to cost $\$ 4,400$ net in 2013, taking into consideration salary, equipment, and laboratory expenses (Betanzo and others, 2015); this per-event cost adds up to an annual net cost of $\$ 105,600$ for bi-monthly sampling, or a total cost of about $\$ 200,000$ if the same institutional overhead ( 0.8 of net) as used in table 2 is applied. If event sampling is necessary, the cost associated with discrete sample collection at a site will increase considerably, depending on the number of events that need to be sampled. Furthermore, low-frequency grab sampling will be subject to aliasing, whereby samples collected may misrepresent conditions. In the Delta, aliasing due to effects of the tidal cycle can be mitigated if careful attention is paid to sampling only during specific points of the cycle, but this approach further increases the cost of grab sampling as fewer samples may be collected in a day. 
Table 2. Detailed estimated 2015 costs of establishing and operating over a 1-year period multiparameter continuous monitoring stations including nitrate and ancillary parameters.

[In situ phosphate and ammonium sensors are listed separately as optional add-ons. Indirect cost at 0.8: A conservative indirect costs factor (also known as overhead rate) of 0.8 was applied to all direct costs]

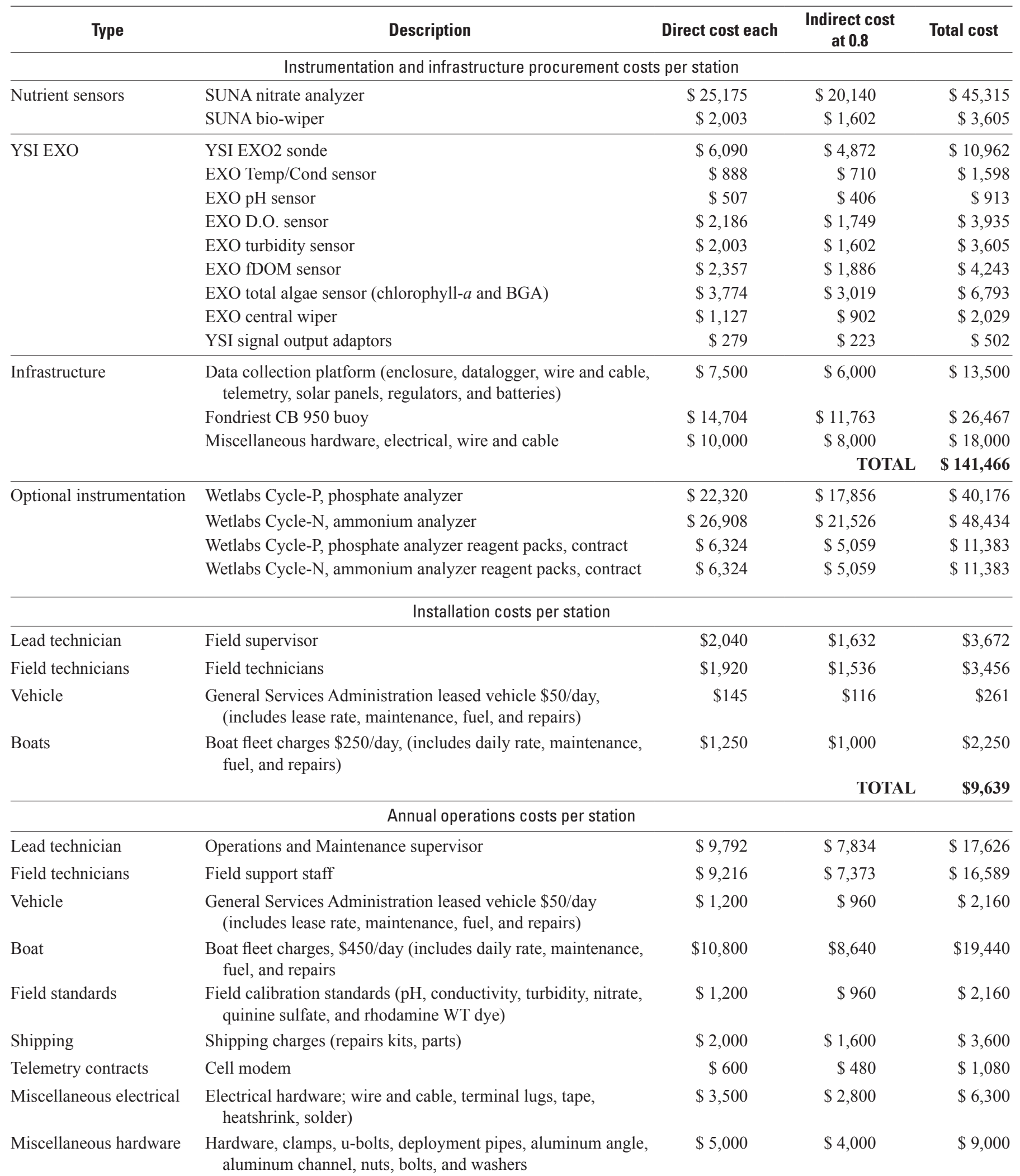


Table 2. Detailed estimated 2015 costs of establishing and operating over a 1-year period multiparameter continuous monitoring stations including nitrate and ancillary parameters. - Continued

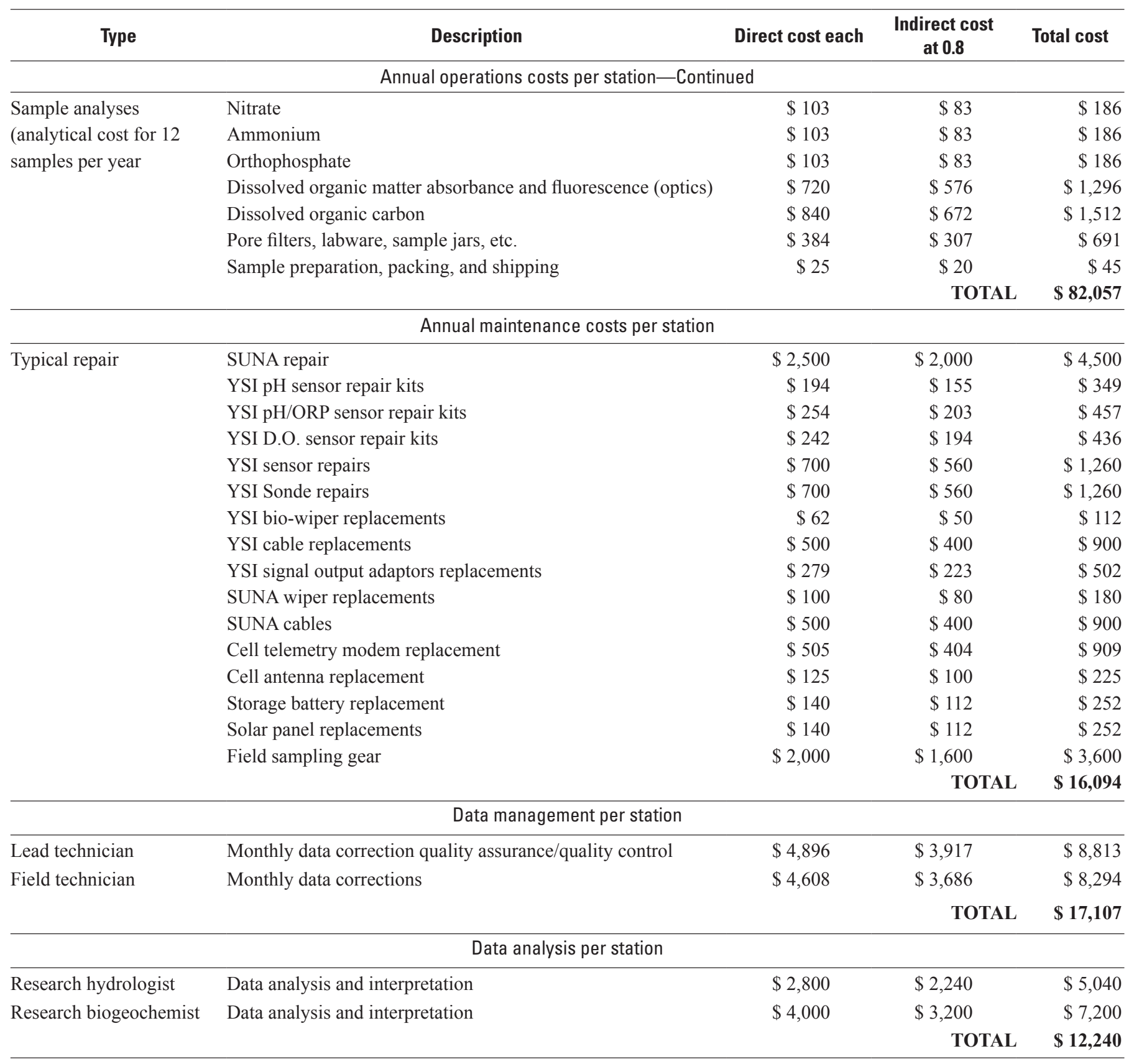


Table 3. Detailed estimated daily 2015 costs for high-frequency mapping of water quality.

[Rows include costs associated with instrument preparation, clean up, boat staging, and same-day travel costs. Indirect cost at 0.8: A conservative indirect cost (also known as, overhead rate) of 0.8 was applied to all direct costs]

\begin{tabular}{|c|c|c|c|c|}
\hline Type & Description & Direct cost & $\begin{array}{l}\text { Indirect cost } \\
\quad \text { at } 0.8\end{array}$ & Total cost \\
\hline Lead technician & Operations and Maintenance supervisor & $\$ 1,296$ & $\$ 1,037$ & $\$ 2,333$ \\
\hline Field technician & Field technician & $\$ 576$ & $\$ 461$ & $\$ 1,037$ \\
\hline Boat operator & Boat operator & $\$ 1,224$ & $\$ 979$ & $\$ 2,203$ \\
\hline Vehicle & $\begin{array}{l}\text { General Services Administration leased vehicle } \$ 50 / \text { day } \\
\text { (includes lease rate, maintenance, fuel, and repairs) }\end{array}$ & $\$ 75$ & $\$ 60$ & $\$ 135$ \\
\hline Boat & $\begin{array}{l}\text { Boat fleet charges } \$ 250 / \text { day (includes daily rate, maintenance, } \\
\text { fuel, and repairs) }\end{array}$ & $\$ 250$ & $\$ 200$ & $\$ 450$ \\
\hline Fuel & & $\$ 250$ & $\$ 200$ & $\$ 450$ \\
\hline Field standards & $\begin{array}{l}\text { Field calibration standards ( } \mathrm{pH} \text {, conductivity, turbidity, } \\
\text { nitrate, quinine sulfate, and rhodamine WT dye) }\end{array}$ & $\$ 40$ & $\$ 32$ & $\$ 72$ \\
\hline Consumables & Miscellaneous filters, hardware, tubing, sample bottles etc. & $\$ 250$ & $\$ 200$ & $\$ 450$ \\
\hline Data specialist & Download, process, correct, and visualize data & $\$ 156$ & $\$ 125$ & $\$ 281$ \\
\hline \multirow[t]{2}{*}{ Supervisory researcher } & Data analysis and interpretation & $\$ 2,000$ & $\$ 1,600$ & $\$ 3,600$ \\
\hline & & & TOTAL & $\$ 11,011$ \\
\hline
\end{tabular}

\section{Planning Principles}

Operational principles that improve network performance and reduce cost are discussed in this section.

\section{Selecting Station Locations}

Although the decision of where to place an HF station may be readily made on the basis of a specific mandate or objective, station placement within a larger network means that one must take into account where stations are relative to each other. The total number of stations in an HF network will be defined by the desired spatial resolution and the available level of funding, but within those constraints, each station or group of stations should have a clear primary purpose. For example, a station could have the primary purpose of:

1. Providing concentration data in support of accurate load calculations, source attribution, and determination of internal process rates and losses of nutrients;
2. Identifying events such as phytoplankton blooms or dissolved oxygen depletion; or

3. Comparing regions with different attributes such as light penetration depth, residence time, amount of wetland, or nutrient concentration.

It may be possible to optimize station locations based on the objectives and priorities of the monitoring program. Some stations could be dedicated to quantifying loads, others could be dedicated to quantifying losses and effects, and others may be established in relation to management actions (for example, flow barriers and restoration projects). In some scenarios, stations could be deployed in clusters to accomplish multiple objectives. In turn, some stations may be installed indefinitely, whereas others may be installed for shorter time periods to document sudden change, support model calibration, and enable determination of process rates for a specific habitat type. 
Where feasible, stations should be located at or near a site where discharge is continuously measured (see fig. 2). Without discharge measurements, it is not possible to calculate fluxes, loads, or rates of loss. However, there may be cases where discharge is not required to meet the purpose of the station. For example, the purpose of the station may be to ensure that a parameter remains below a threshold value, or to document the occurrence of harmful algal blooms in relation to nutrient concentrations, neither of which requires concomitant measurement of discharge, or calculation of flux. The number and type of variables measured at each station in a network generally should correspond to the individual, site-specific purpose of each station as well as to its purpose within the larger network.

Within the station network, each station also should have a clear priority to guide the order of network expansion, in addition to the priority for station support and maintenance when the inevitable failures occur. The prioritization is obviously related to the primary monitoring objectives of the network.

\section{Station Attributes}

Stations should be capable of two-way communication, permitting remote troubleshooting of instruments or software and reducing the number of visits necessary by network personnel, which can substantially reduce costs. Two-way communication also can provide information about the specific nature of an operational problem, permitting personnel to prepare for the necessary repairs and again reducing the number of trips to the station. Two-way communication also permits station operators to make software changes or other operational changes remotely, as may be desired during an unusual event when a high frequency of data may be useful.

Whenever possible, stations should be accessible under all anticipated conditions to ensure that stations may be serviced during high- or low-flow conditions, when the data may be particularly valuable because it represents an unusual event in the time series.

Station infrastructure should be capable of hosting more than the immediate instrumentation for several reasons. First, the field of in situ water quality instrumentation is rapidly developing, and it may be desirable to add additional instrumentation to the stations as it becomes available. Second, it may be useful to deploy multiple instruments of the same type for cross validation. Third, it may be useful to deploy instruments at different levels in the water column or at different locations within a channel to evaluate vertical or lateral variability. Finally, stations also should be able to support special or intensive studies that use instruments presently only capable of short-term deployments, such as phosphate or ammonium instruments.

There could be a diversity of station types in the network, across increasing levels of complexity or intensity of measurement to accomplish the objectives of the network. However, it often is useful to have the capacity for a diversity of capabilities to assess the quality of network data-for example, to explore if measurements made at one location in the water column are representative of conditions across the channel, or representative of the full depth of the channel.

It often is useful to develop one station as a testbed for new instrumentation, new operations, or new software. Such a station would be configured to allow addition of the redundant data collection platform without interfering with the primary measurements made at the station. It also should have additional deployment infrastructure to accommodate future instrumentation.

There should be a stand-by capacity in the network for rapid response to station failure and for emplacement of new temporary stations to ensure the minimal loss of data, and also to permit collection of data at nonstandard locations or during unusual events.

\section{Quality Assurance}

The first principle of quality assurance for a real-time, HF network is to look at the incoming data daily. Data should be examined to ensure that the reported values are within normative ranges for the contemporaneous environmental conditions, and that the reporting intervals are correct. If burst sampling (collection of many data points over a short period of time) is used, the reproducibility of the samples within the burst should be examined. For example, the coefficient of variation of the data should meet predetermined criteria. Results should be compared with those from nearby stations to help identify sensor drift or malfunction.

Discrete water samples should be collected at the HF station while it is taking measurements or automatic samples, preferably during every scheduled site visit when there is already an investment of time and labor. If possible, to further validate station performance, additional samples should be collected over a period of particularly high constituent variability, such as over a tidal cycle or during storm events. 


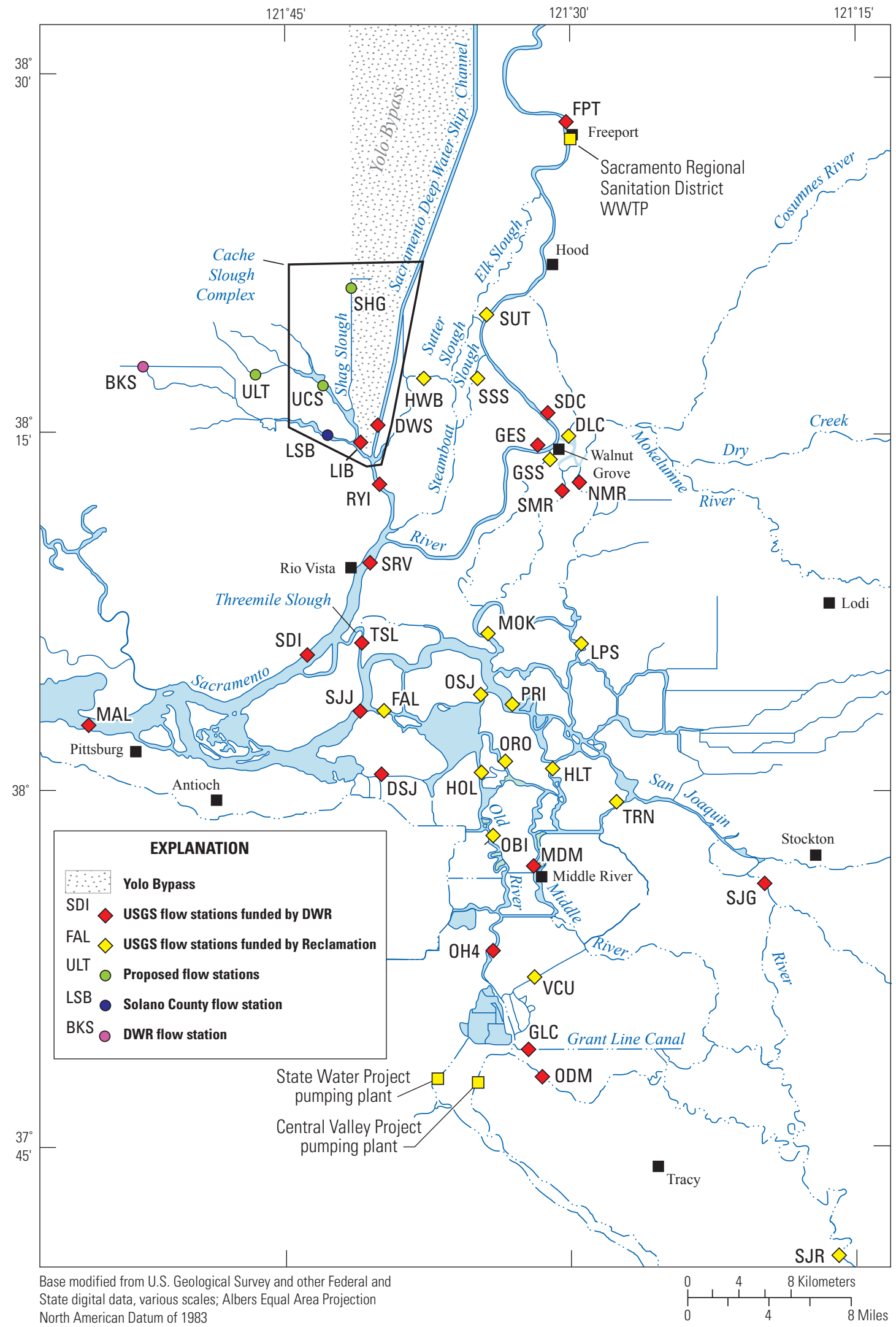

Figure 2. Existing and proposed flow-monitoring stations, selected pumping stations, and selected wastewater treatment plants (WWTPs) in the Sacramento-San Joaquin Delta, northern California. Station abbreviations are defined in appendix table A1. DWR, California Department of Water Resources; Reclamation, Bureau of Reclamation; USGS, U.S. Geological Survey. 
Another principle of quality assurance is consistency, to ensure that the data are collected to a common standard, including development of written guidelines and standard operating procedures. It also includes training for individuals who will be involved in installation, operation, or maintenance of stations in the network. These individuals should periodically refresh their training to ensure data quality, compatibility, and continuity of operations.

Careful records should be maintained for all metadata associated with collection of any data point, and these metadata should be linked to the data in the repository, including information such as the instrument manufacturer, type, serial number, and condition notes for all system components. Metadata also should include details such as how the instrument was mounted, the length of cable, etc. Photographic documentation of atypical site, sample, and equipment conditions also should be collected and managed as metadata records. This information is invaluable for troubleshooting and identifying anomalous data.

If multiple administrative units, research groups, or agencies are operating the network, to ensure maximum inter-comparability of data, common standards and practices for instrument qualification, instrument calibration, instrument operation, data collection, and data quality assurance and control should be negotiated and adopted by all groups collecting HF data as part of the network.

Periodic reviews of the HF monitoring program should be conducted by outside experts involved in similar monitoring from other hydrologic systems. The review should assess whether the Delta monitoring is meeting its data quality objectives and whether the information provided by the network is being used to maximum effect. The review also could assess the extent to which the network and resulting data are meeting the stakeholders' needs and monitoring purposes set out in the guidance documents.

\section{Data Processing}

Processing HF data and ensuring data quality often are implemented by quasi-automated routines, but these are best conceptualized as a multistep process. First, it requires an initial data evaluation to assess if the instrument performance metrics indicate that the data are valid and within nominal or historical bounds, and whether they generally meet expectations based on the response of nearby stations, recent changes in hydrology, etc. Once data are known to be of high quality, data corrections are applied, including corrections for offsets, drift, and interferences such as temperature, turbidity, or dissolved constituents (Wagner and others, 2006; Downing and others, 2012). The chemical time series data are then integrated with the hydrodynamic data (which require their own quality assurance procedures) to calculate instantaneous flux and cumulative loads by applying, for example, rating and cross-section corrections. It is only then that the data are passed off for second-level review.

The process of ensuring data quality and integrity is time-consuming and must be done by knowledgeable staff. Past experience has shown that applying data visualization tools as well as providing data as rapidly as possible to end users facilitates the process of developing well-vetted, highquality datasets.

There inevitably will be gaps in the data as the result of instrument failures or exclusion of data that fail to pass quality criteria. These gaps often interfere with the analysis of network data. Other environmental fields have addressed this problem by developing multi-parameter approaches to estimate "imputed" values for infilling lost data and for calculating the uncertainty of doing so. Similar techniques that rely on strong relationships between covariant parameters could be developed for use in HF nutrients monitoring networks. Once these techniques are operational, the Delta monitoring program's datasets can be reprocessed to fill data gaps, and then revised time series data and derivatives could be published along with the associated uncertainty.

\section{Example Network Plans}

The three network examples described separately in the following subsections show how to use the list of questions in section, "Considerations" to plan and evaluate potential HF network designs of different capabilities and costs, and to compare their utility. Although these three examples loosely follow the three HF monitoring program types discussed in section, "Background," they are not intended to directly correspond to those program types. There are numerous possible combinations of monitoring questions, objectives, and consequent configurations for network designs depending on the goals and available resources; the three examples provided are intended to help foster the types of discussion needed to establish a realistic plan. 


\section{High-Frequency Monitoring Network Example 1-A Minimal Network Focused on Concentrations and Loads}

The network goals are to document variability and temporal changes in the magnitude of nitrogen loads to the Delta for the purpose of evaluating nutrient-reduction strategies and estimating their effects on the Delta and downstream environments.

The network consists of three stations along the eastern margin of the Delta (tables 4 and 5, fig. 3) that capture the principal sources of nutrients entering the Delta (Novick and others, 2015). Stations on the Sacramento and San Joaquin Rivers are located downstream of the major WWTP discharges because these are known to be significant drivers of nutrient concentrations in these rivers. The third station is at the downstream end of the Cache Slough Complex in the northern Delta, which at times receives nutrient inputs from the Yolo Bypass.
With this design, there will be an ability to relate overall loading to observed effects within the Delta, but there will be no ability to relate nutrient concentrations to those effects except in the broadest sense because there is no data with which to assess effects observed in the Delta, limiting the usefulness for establishing target threshold values. There also will be no ability to estimate internal sources, sinks, transformations, or rates of processes.

Although the network will provide information about daily or weekly loads entering the Delta, it will not provide any additional ability to act as an "early warning" system for phytoplankton blooms, spills, or other event-driven or ephemeral water quality conditions in the central Delta unless and until predictive relationships are established between these events and nutrient loading. However, even with these types of predictive relationships, early warnings derived from stations along the margins of the Delta will never provide the same level of reliability and accuracy as warnings raised by stations placed in the central Delta.

Table 4. Three stations proposed as part of high-frequency Monitoring Network Example 1, Sacramento-San Joaquin Delta, northern California.

\begin{tabular}{lcc}
\hline \multicolumn{1}{c}{ Station name } & $\begin{array}{c}\text { Station } \\
\text { abbreviation } \\
\text { (see fig. 3) }\end{array}$ & Station primary purpose \\
\hline San Joaquin River at Stockton & SJG (C) & $\begin{array}{c}\text { Monitor fluxes and loads from San Joaquin Valley and Stockton } \\
\text { Regional Wastewater Treatment Facility. }\end{array}$ \\
$\begin{array}{l}\text { Sacramento River at Walnut Grove, } \\
\text { above Georgianna Slough }\end{array}$ & SDC (A) & $\begin{array}{c}\text { Monitor fluxes from Sacramento Valley and Sacramento storm } \\
\text { discharge and Sacramento Wastewater Treatment Facility. }\end{array}$ \\
\begin{tabular}{l} 
Cache Slough at Ryer Island \\
\hline
\end{tabular} & RYI (B) & Monitor fluxes from Yolo Bypass, Miner Slough, and Cache Slough \\
\hline
\end{tabular}

Table 5. Estimated 2015 costs for high-frequency Monitoring Network Example 1, consisting of three stations, Sacramento-San Joaquin Delta, northern California.

[Initial costs include equipment purchases and installation, and operations and maintenance costs are based on a 12-months/annual basis. See table 2 for details]

\begin{tabular}{|c|c|c|}
\hline Example 1 & $\begin{array}{l}\text { Initial } \\
\text { costs }\end{array}$ & $\begin{array}{l}\text { Operations and } \\
\text { Maintenance } \\
\text { costs }\end{array}$ \\
\hline Instrumentation and infrastructure & $\$ 424,398$ & \\
\hline Installation & $\$ 28,919$ & \\
\hline Operations & & $\$ 246,172$ \\
\hline Maintenance & & $\$ 48,281$ \\
\hline Reserve and rapid response instrumentation & $\$ 113,000$ & $\$ 74,000$ \\
\hline Quality assurance and data management & & $\$ 62,000$ \\
\hline Data analysis & & $\$ 44,000$ \\
\hline TOTALS & $\$ 566,318$ & $\$ 474,453$ \\
\hline
\end{tabular}

The network will not be particularly useful for targeted sampling of beneficial or harmful algal blooms, or to relate nutrient loading to habitat quality in the Delta.

The data will be primarily useful for managers seeking to document the efficacy of BMPs, other nutrient reduction efforts, and TMDLs for detecting trends in nutrient loads to the Delta, and for evaluating changes in timing of those loads.

Network Example 1 best addresses initial assessment question SPLP-1B; partially addresses ST-1B, SPLP-1A, and SPLP-1G; and provides information for initial assessment question FS-1 (table 1). Because only inputs and outputs are monitored, this example does not address important data gaps associated with subregions of the Delta (ST-1C). 


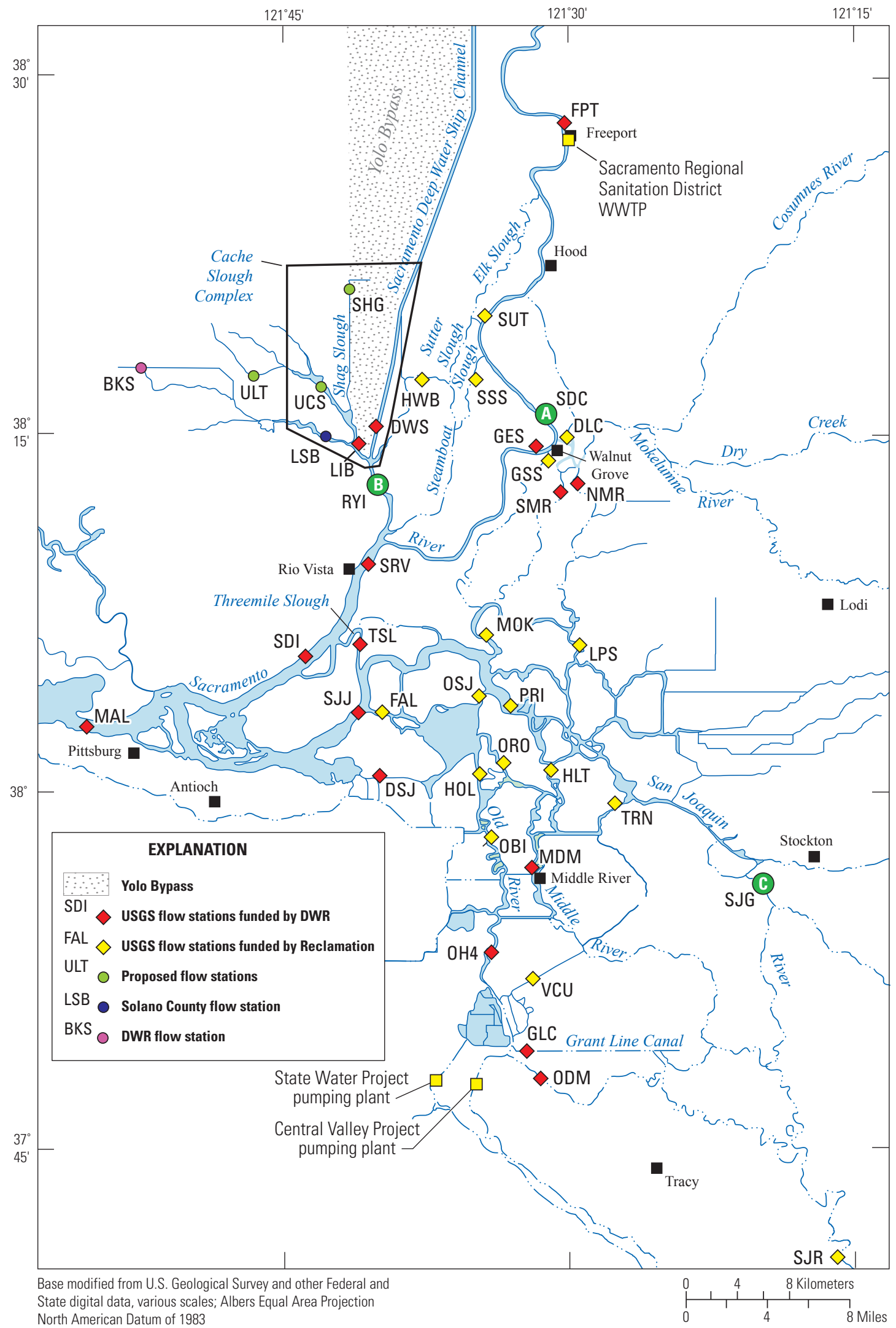

Figure 3. Three nutrients monitoring stations (circled letters) proposed as part of high-frequency Monitoring Network Example 1 in relation to existing and proposed flow-monitoring stations in the Sacramento-San Joaquin Delta, northern California. Station A is on the Sacramento River, station B is at the entrance to the Cache Slough Complex, and station C is on the San Joaquin River. See table 4 for details. DWR, California Department of Water Resources; Reclamation, Bureau of Reclamation; USGS, U.S. Geological Survey; WWTP, wastewater treatment plant. 


\section{High-Frequency Monitoring Network Example 2-A Network Focused on Internal Sources, Processes, and Rates}

The network goals are to:

- Document internal fluxes and loads in the Delta, including loading of nitrogen and phosphorus from island drains and wetlands;

- Evaluate the extent to which nutrients are attenuated through interaction with wetlands and submerged islands;

- Include monitoring of nutrient concentrations of water bound for export; and

- Presume external loadings to the Delta are adequately constrained by monthly sampling programs and discharger reporting.
The network includes HF monitoring stations across the central and northern Delta, and routes to export facilities (tables 6 and 7, fig. 4).

The intent is to be able to quantify internal nutrient fluxes, load transformations, and loss processes (including nitrogen and phosphorus) by mass balance between stations. There will be an ability to relate instantaneous concentrations to observed effects in the Delta, and, thus, to infer effects of changes of external and internal loading. These data may be useful in establishing concentration targets to achieve specific habitat quality criteria in the Delta. Internal loads and rates of loss will be quantitatively estimated, improving modeling of nutrient concentrations and loads.

The network will provide real-time data for the Delta, and thus may be used as a reliable and accurate "early warning" system for beneficial or harmful algal blooms or other ecological conditions where targeted conditional sampling may be useful.

Table 6. Six stations proposed as part of high-frequency Monitoring Network Example 2, Sacramento-San Joaquin Delta, northern California.

\begin{tabular}{lll}
\hline \multicolumn{1}{c}{ Station name } & $\begin{array}{c}\text { Station } \\
\text { abbreviation } \\
\text { (see fig. 4) }\end{array}$ & \multicolumn{1}{c}{ Station primary purpose } \\
\hline Sacramento River at Rio Vista & SRV (A) & Monitor nutrient concentrations and fluxes in Sacramento River. \\
Jersey Point & SJJ (B) & $\begin{array}{l}\text { Monitor nutrient concentrations and fluxes in the San Joaquin mainstem. } \\
\text { Assess contributions from Central Delta Islands. }\end{array}$ \\
Old River & OH4 (F) & Assess nutrient by mass balance contributions from Central Delta Islands. \\
Middle River & MDM (E) & Assess mass balance contributions from Central Delta Islands. \\
Middle River near Holt & HLT (D) & Assess exchange contributions from Central Delta Islands. \\
Old River at Franks Tract & OSJ (C) & Assess exchange contributions from Central Delta Islands. \\
\hline
\end{tabular}

Table 7. Estimated 2015 costs for high-frequency Monitoring Network Example 2, consisting of six stations, Sacramento-San Joaquin Delta, northern California.

[Initial costs include equipment purchases and installation, and operations and maintenance costs are based on a 12-months/annual basis. See table 2 for details]

\begin{tabular}{|c|c|c|}
\hline Example 2 & $\begin{array}{l}\text { Initial } \\
\text { costs }\end{array}$ & $\begin{array}{l}\text { Operations and } \\
\text { Maintenance } \\
\text { costs }\end{array}$ \\
\hline Instrumentation and infrastructure & $\$ 848,797$ & \\
\hline Installation & $\$ 57,839$ & \\
\hline Operations & & $\$ 492,343$ \\
\hline Maintenance & & $\$ 96,563$ \\
\hline Reserve and rapid response instrumentation & $\$ 136,000$ & $\$ 88,000$ \\
\hline Quality assurance and data management & & $\$ 103,000$ \\
\hline \multirow[t]{2}{*}{ Data analysis } & & $\$ 73,000$ \\
\hline & $\$ 1,042,636$ & $\$ 852,906$ \\
\hline
\end{tabular}

The data will be useful for managers documenting the persistence, transit times, and effects of nutrients in the Delta; for establishing trends in nutrient loads internal to the Delta; and for relating nutrient concentrations in the Delta to flows and exports.

Network Example 2 best addresses initial assessment questions ST-1, ST-1A, ST-2, SPLP-1C; and partially addresses initial assessment questions ST-1B, ST-2A, SPLP-1A, SPLP-1E, SPLP-1F, FS-1 (table 1). Because tributary inputs and outputs are not included, and the spatial distribution of stations in the central Delta is minimal, this example does not allow assessment of the importance of different nutrient sources (SPLP-1B, SPLP-1D, and SPLP-1G) and does not fully address important data gaps associated with subregions of the Delta (ST-1C). 


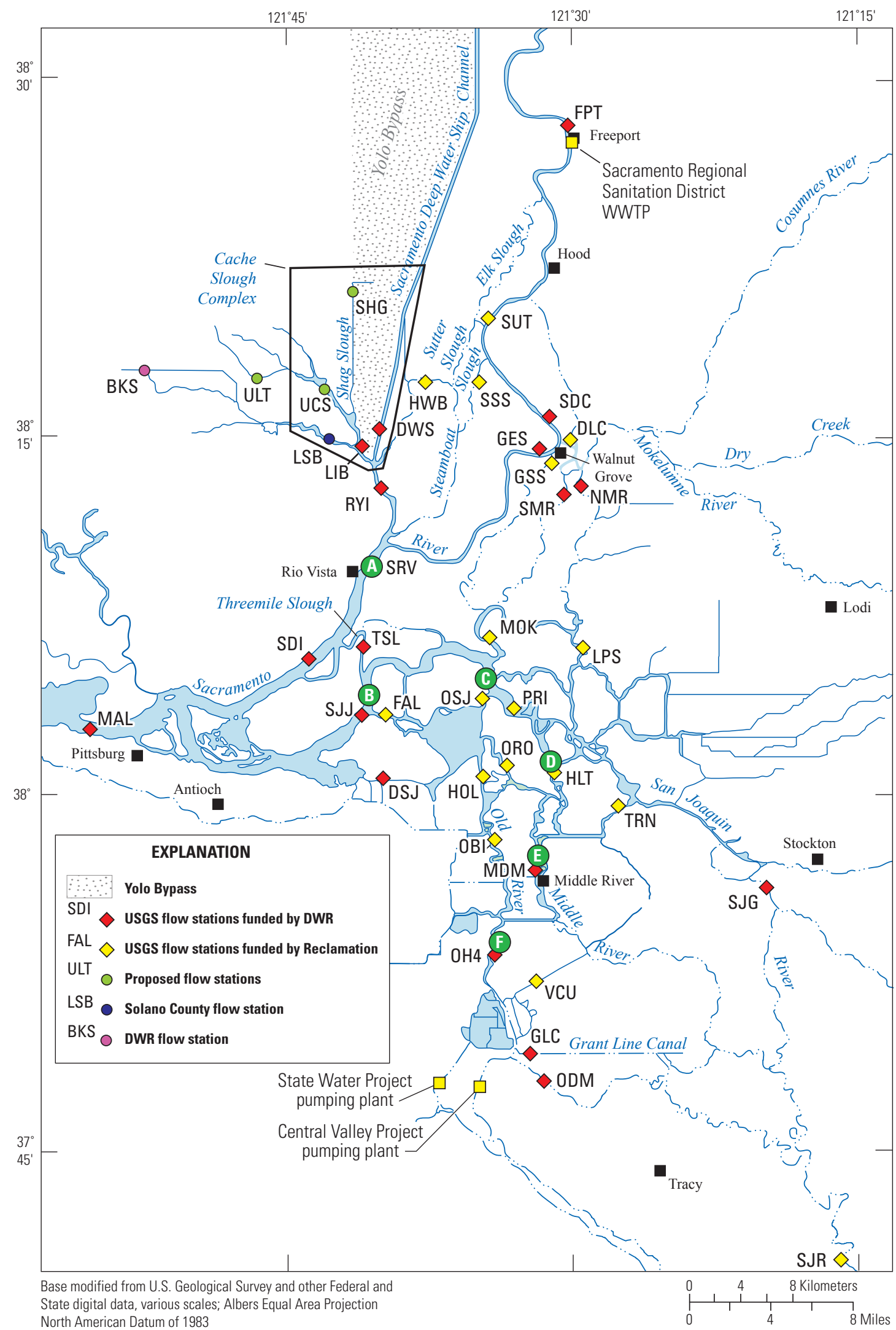

Figure 4. Six nutrients monitoring stations (circled letters) proposed as part of high-frequency Monitoring Network Example 2 in relation to existing and proposed flow-monitoring stations in the Sacramento-San Joaquin Delta, northern California. See table 6 for station details. DWR, California Department of Water Resources; Reclamation, Bureau of Reclamation; USGS, U.S. Geological Survey; WWTP, wastewater treatment plant. 


\section{High-Frequency Monitoring Network Example 3-A Comprehensive Network Focused On Ecosystem-Level Effects}

For the third and most comprehensive example, the network goals are to:

- Document loads to and within the Delta, including loading of nitrogen and phosphorus;

- Evaluate rates and extent of nutrients attenuated through interaction with wetlands and submerged islands;

- Evaluate habitat conditions and relationship between nutrients, environmental factors, and phytoplankton abundance;
- Include monitoring of dissolved organic carbon, bromide, and nutrient concentrations in water bound for export; and

- Monitor loads to and permit analysis of effects of nutrients from the Delta on ecosystem responses in the upper San Francisco Estuary, such as the effects of nutrient forms and ratios on phytoplankton production (Glibert, 2010).

The spatial extent of the network spans the central and northern Delta, and routes to export facilities (tables 8 and 9, fig. 5).

Table 8. Eighteen stations proposed as part of high-frequency Monitoring Network Example 3, Sacramento-San Joaquin Delta, northern California.

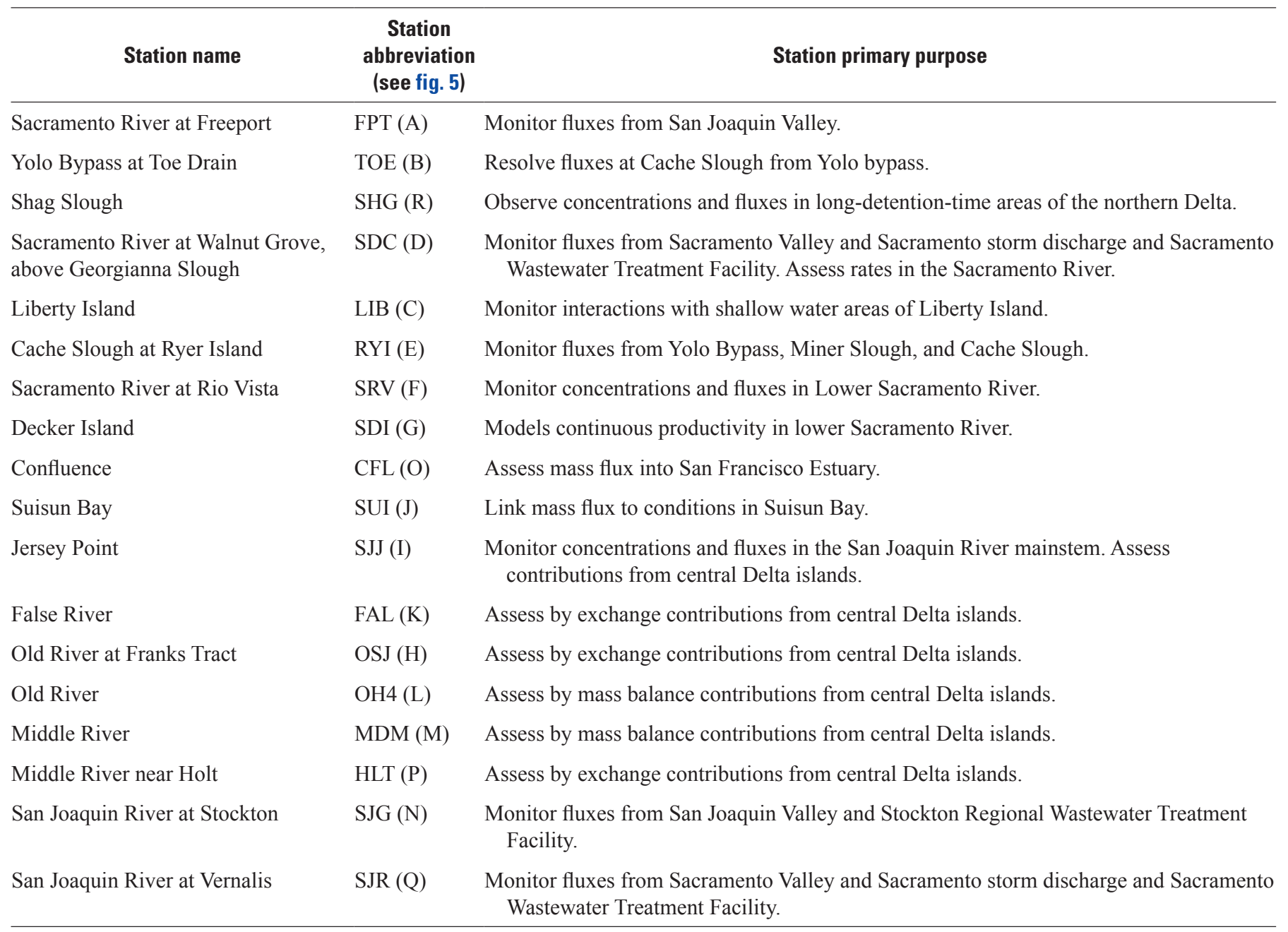


Table 9. Estimated 2015 costs for high-frequency Monitoring Network Example 3, consisting of 18 high-frequency monitoring stations, Sacramento-San Joaquin Delta, northern California.

[Initial costs include equipment purchases and installation, and operations and maintenance costs are based on a 12-months/annual basis. See table 2 for details]

\begin{tabular}{|c|c|c|}
\hline Example 3 & $\begin{array}{l}\text { Initial } \\
\text { costs }\end{array}$ & $\begin{array}{l}\text { Operations and } \\
\text { Maintenance } \\
\text { costs }\end{array}$ \\
\hline Instrumentation and infrastructure & $\$ 2,546,391$ & \\
\hline Installation & $\$ 173,517$ & \\
\hline Operations & & $\$ 1,477,029$ \\
\hline Maintenance & & $\$ 289,688$ \\
\hline Reserve and rapid response instrumentation & $\$ 272,000$ & $\$ 177,000$ \\
\hline Quality assurance and data management & & $\$ 216,000$ \\
\hline \multirow[t]{2}{*}{ Data analysis } & & $\$ 154,000$ \\
\hline & $\$ 2,991,908$ & $\$ 2,313,718$ \\
\hline
\end{tabular}

The intent is to enable analysts to quantify the internal loading, including nitrogen and phosphorus by calculating the mass balance between stations. The density of stations allows instantaneous concentrations to be linked to observed effects in the Delta, and, in combination with the network of flow stations, to infer ecological effects caused by changes of external and internal loading. The resulting data may be useful in establishing concentration targets to achieve specific habitat quality criteria. Internal loads and rates of loss will be quantitatively estimated, improving modeling of nutrient concentrations and loads.

The network will provide real-time data, and thus may be used as an "early warning" system for beneficial or harmful algal blooms or other ecological conditions, providing not only lead time to prepare but also signalling where targeted conditional sampling may be useful.

The data will be useful for managers documenting the persistence, transit times, and effects of nutrients in the Delta; for establishing trends in nutrient loads internal to the Delta; and for relating nutrient concentrations in the Delta to flows and exports.

Network Example 3 addresses the broadest range of the initial assessment questions listed in table 1, although there may still remain data gaps associated with specific subregions of the Delta (ST-1C) that would require targeted monitoring efforts. 


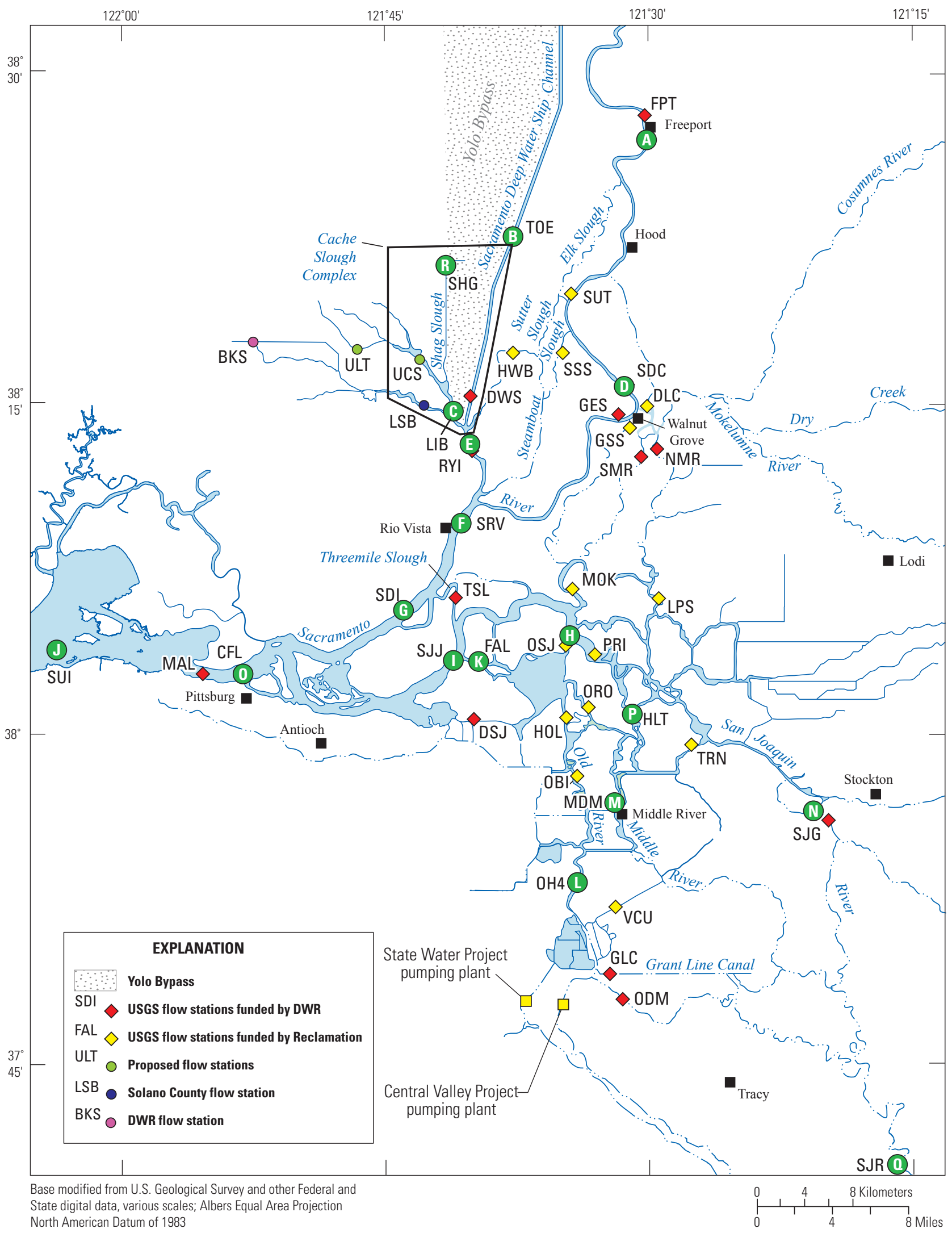

Figure 5. Eighteen stations (circled letters) proposed as part of high-frequency Monitoring Network Example 3 in relation to existing and proposed flow-monitoring stations in the Sacramento-San Joaquin Delta, northern California. See table 8 for station details. DWR, California Department of Water Resources; Reclamation, Bureau of Reclamation; USGS, U.S. Geological Survey. 


\section{Summary and Conclusions}

The challenge in designing a monitoring program first requires the objectives to be clearly defined, from which follows what parameters should be measured, and at what temporal and spatial frequency they should be collected to sufficiently provide comprehensive, relevant, and robust information. In a complex system like the Sacramento-San Joaquin Delta of northern California, adding additional stations will, to a point, help us better:

- Quantify nutrient concentrations, fluxes and loads;

- Identify nutrient sources, sinks, and transformations;

- Understand ecosystem drivers, processes, and effects; and

- Detect and predict changes in these processes resulting over time due to natural factors and (or) human action.

Although a high-frequency (HF) monitoring component can significantly contribute to addressing these issues, current limitations in our understanding of ecological process and in the capabilities of the technology indicate that HF monitoring will be able to provide maximum benefit in conjunction with integrated research, development, and modeling programs. Design of an HF network should carefully consider the existing and future uses to which the HF data will be applied and how these and related data should be served to users. Furthermore, given that HF monitoring technology is in its infancy, the network design should anticipate and build in the capacity to expand scope as appropriate when future technologies offer advances that align with monitoring goals and information needs.

\section{Acknowledgments}

The authors gratefully acknowledge the Bureau of Reclamation, which for years has supported our efforts to build, maintain, and improve a nutrient and biogeochemical monitoring network in the northern Sacramento-San Joaquin Delta. Without their support, this report would not be possible. We would like to thank the Delta Regional Monitoring Program (RMP) and the San Francisco Estuary Institute for supporting preparation of this report series.

Furthermore, we would like to express our appreciation to Angela Hansen, Elizabeth Stumpner, and Katy O'Donnell at the U.S. Geological Survey, without whom we would not have completed this report. Finally, we would like to thank Phil Trowbridge, Thomas Jabusch, Meg Sedlak, Joe Domagalski, Stephen McCord, Anke Muller-Solger, and members of the Delta RMP Nutrient Technical Advisory Committee, whose feedback and comments have improved the quality of this report.

\section{References Cited}

Bergamaschi, B.A., Fleck, J.A., Downing, B.D., Boss, E., Pellerin, B.A., Ganju, N.K., Schoellhamer, D.H., Byington, A.A., Heim, W.A., Stephenson, M., and Fujii, R., 2012, Mercury dynamics in a San Francisco Estuary tidal wetland-Assessing dynamics using in situ measurements: Estuaries and Coasts, v. 35, no. 4, p. 1,036-1,048.

Betanzo, E.A., Choquette, A.F., and Hayes, L., 2015, Water data to answer urgent water policy questions: Monitoring design, available data and filling data gaps for determining the effectiveness of agricultural management practices for reducing tributary nutrient loads to Lake Erie-Addendum describing new, expanded, and planned monitoring sites: Northeast-Midwest Institute Report, 27 p., http://www. nemw.org/wp-content/uploads/2015/06/Final-NutrientAddendum.pdf.

Burau, J., Ruhl, C., and Work, P., 2016, Innovation in monitoring-The U.S. Geological Survey Sacramento-San Joaquin River Delta, California, flow-station network: U.S. Geological Survey Fact Sheet 2015-3061, 6 p.

Carpenter, K.D., Kraus, T.E.C., Goldman, J.H., Saraceno, J.F., Downing, B.D., Bergamaschi, B.A., McGhee, G., and Triplett, T., 2013, Sources and characteristics of organic matter in the Clackamas River, Oregon, related to the formation of disinfection by-products in treated drinking water: U.S. Geological Survey Scientific Investigations Report 2013-5001, 78 p.

Conley, D.J., Paerl, H.W., Howarth, R.W., Boesch, D.F., Seitzinger, S.P., Havens, K.E., Lancelot, C., and Likens, G.E., 2009, Ecology - Controlling eutrophicationNitrogen and phosphorus: Science, v. 323, no. 5,917, p. 1,014-1,015.

Cornwell, J.C., Glibert, P.M., and Owens, M.S., 2014, Nutrient fluxes from sediments in the San Francisco Bay Delta: Estuaries and Coasts, v. 37, no. 5, p. 1,120-1,133.

Crawford, J.T., Loken, L.C., Casson, N.J., Smith, C., Stone, A.G., and Winslow, L.A., 2015, High-speed limnologyUsing advanced sensors to investigate spatial variability in biogeochemistry and hydrology: Environmental Science and Technology, v. 49, no. 1, p. 442-450.

Delta Regional Monitoring Program Technical Advisory Committee, 2015, Monitoring design summary: Richmond, California, Aquatic Science Center, June 2015, http://www. waterboards.ca.gov/centralvalley/water_issues/delta_water quality/delta_regional_monitoring/wq_monitoring_plans/ drmp_monitoring_design.pdf. 
Delta Stewardship Council, 2016, Delta Science Plan: accessed May 2016, at http://www.deltacouncil.ca.gov/ sites/default/files/2016/07/Delta\%20Science\%20Plan update $\% 20$ FINAL $\% 20$ May\%205\%202016\%20v2.pdf.

DiGennaro, B., Reed, D., Swanson, C., Hastings, L., Hymanson, Z., Healey, M., Siegel, S., Cantrell, S., and Herbold, B., 2012, Using conceptual models in ecosystem restoration decision making-An example from the Sacramento-San Joaquin River Delta, California: San Francisco Estuary and Watershed Science, v. 10, no. 3, 15 p.

Domagalski, J., and Saleh, D., 2015, Sources and transport of phosphorus to rivers in California and adjacent States, US, as determined by SPARROW modeling: Journal of the American Water Resources Association, v. 51, no. 6, p. $1,463-1,486$.

Downing, B.D., Bergamaschi, B.A., Kendall, C., Kraus, T.E.C., and von Dessonneck, T.S., 2016, Using continuous water isotope measurements to map water residence time in hydrodynamically complex tidal environments: Environmental Science and Technology, v. 50, no. 24, p. 13,387-13,396.

Downing, B.D., Bergamaschi, B.A., and Kraus, T.E.C., 2017, Synthesis of data from high-frequency nutrient and associated biogeochemical monitoring for the SacramentoSan Joaquin Delta, northern California: U.S. Geological Survey Scientific Investigations Report 2017-5066, 28 p., https://doi.org/10.3133/sir20175066.

Downing, B.D., Pellerin, B.A., Bergamaschi, B.A., Saraceno, J.F., and Kraus, T.E.C., 2012, Seeing the light - The effects of particles, dissolved materials, and temperature on in situ measurements of DOM fluorescence in rivers and streams: Limnology and OceanographyMethods, v. 10, p. 767-775.

Fichot, C.G., Downing, B.D., Bergamaschi, B.A., WindhamMyers, L., Marvin-DiPasquale, M., Thompson, D.R., and Gierach, M.M., 2016, High-resolution remote sensing of water quality in the San Francisco Bay-Delta Estuary: Environmental Science and Technology, v. 50, no. 2, p. 573-583, http://dx.doi.org/10.1021/acs.est.5b03518.

Foe, C., Ballard, A., and Fong, S., 2010, Nutrient concentrations and biological effects in the Sacramento-San Joaquin Delta: Sacramento, Central Valley Regional Water Quality Control Board, 90 p.

Glibert, P.M., 2010, Long-term changes in nutrient loading and stoichiometry and their relationships with changes in the food web and dominant pelagic fish species in the San Francisco Estuary, California: Reviews in Fisheries Science, v. 18, no. 2, p. 211-232.
Glibert, P.M., Dugdale, R.C., Wilkerson, F., Parker, A.E., Alexander, J., Antell, E., Blaser, S., Johnson, A., Lee, J., Lee, T., Murasko, S., and Strong, S., 2014, Major-but rare-spring blooms in 2014 in San Francisco Bay Delta, California, a result of the long-term drought, increased residence time, and altered nutrient loads and forms: Journal of Experimental Marine Biology and Ecology, v. 460, p. 8-18.

Graham, J.L., 2007, Harmful algal blooms: U.S. Geological Survey Fact Sheet 2006-3147, 2 p.

Jassby, A., 2008, Phytoplankton in the upper San Francisco Estuary-Recent biomass trends, their causes, and their trophic significance: San Francisco Estuary and Watershed Science, v. 6, no. 1, 24 p.

Jassby, A.D., and Cloern, J.E., 2000, Organic matter sources and rehabilitation of the Sacramento-San Joaquin Delta (California, USA): Aquatic Conservation-Marine and Freshwater Ecosystems, v. 10, no. 5, p. 323-352.

Kratzer, C.R., Kent, R., Seleh, D.K., Knifong, D.L., Dileanis, P.D., and Orlando, J.L., 2011, Trends in nutrient concentrations, loads, and yields in streams in the Sacramento, San Joaquin, and Santa Ana Basins, California, 1975-2004: U.S. Geological Survey Scientific Investigations Report 2010-5228, 112 p.

Kraus, T., Bergamaschi, B., Hernes, P., Spencer, R., Stepanauskas, R., Kendall, C., Losee, R., and Fujii, R., 2008, Assessing the contribution of wetlands and subsided islands to dissolved organic matter and disinfection byproduct precursors in the Sacramento-San Joaquin River Delta-A geochemical approach: Organic Geochemistry, v. 39 , no. 9 , p. $1,302-1,318$.

Kraus, T.E.C., Bergamaschi, B.A., and Downing, B.D., 2017, An introduction to high-frequency nutrient monitoring for the Sacramento-San Joaquin Delta, northern California: U.S. Geological Survey Scientific Investigations Report 2017-5071, 41 p., https://doi.org/10.3133/sir20175071.

Lehman, P.W., Marr, K., Boyer, G.L., Acuna, S., and Teh, S. J., 2013, Long-term trends and causal factors associated with Microcystis abundance and toxicity in San Francisco Estuary and implications for climate change impacts: Hydrobiologia, v. 718, no. 1, p. 141-158.

Morgan-King, T.L., and Schoellhamer, D.H., 2013, Suspended-sediment flux and retention in a backwater tidal slough complex near the landward boundary of an estuary: Estuaries and Coasts, v. 36, no. 2, p. 300-318. 
Novick, E., Holleman, R., Jabusch, T., Sun, J., Trowbridge, P., Senn, D., Guerin, M., Kendall, C., Young, M., and Peek, S., 2015, Characterizing and quantifying nutrient sources, sinks and transformations in the Delta-Synthesis, modeling, and recommendations for monitoring: Richmond, California, San Francisco Estuary Institute, 28 p.

O’Donnell, K., 2014, Nitrogen sources and transformations along the Sacramento River-Linking wastewater effluent releases to downstream nitrate: Sacramento, California State University, Master's thesis, $52 \mathrm{p}$.

Paerl, H.W., and Otten, T.G., 2016, Duelling 'CyanoHABs'Unravelling the environmental drivers controlling dominance and succession among diazotrophic and non-N2fixing harmful cyanobacteria: Environmental Microbiology, v. 18 , no. 2, p. 316-324.

Parker, A.E., Dugdale, R.C., and Wilkerson, F.P., 2012, Elevated ammonium concentrations from wastewater discharge depress primary productivity in the Sacramento River and the northern San Francisco Estuary: Marine Pollution Bulletin, v. 64, no. 3, p. 574-586.

Pellerin, B.A., Bergamaschi, B.A., Downing, B.D., Saraceno, J.F., Garrett, J.D., and Olsen, L. D., 2013, Optical techniques for the determination of nitrate in environmental waters - Guidelines for instrument selection, operation, deployment, maintenance, quality assurance, and data reporting: U.S. Geological Survey Techniques and Methods, book 1, chap. D5, 37 p.

Pellerin, B.A., Bergamaschi, B.A., Gilliom, R.J., Crawford, C.G., Saraceno, J., Frederick, C.P., Downing, B.D., and Murphy, J.C., 2014, Mississippi River nitrate loads from high frequency sensor measurements and regression-based load estimation: Environmental Science and Technology, v. 48 , no. 21 , p. $12,612-12,619$.

Pellerin, B.A., Downing, B.D., Kendall, C., Dahlgren, R.A., Kraus, T.E.C., Saraceno, J., Spencer, R.G.M., and Bergamaschi, B.A., 2009, Assessing the sources and magnitude of diurnal nitrate variability in the San Joaquin River (California) with an in situ optical nitrate sensor and dual nitrate isotopes: Freshwater Biology, v. 54, no. 2, p. 376-387.
Pellerin, B.A., Saraceno, J.F., Shanley, J.B., Sebestyen, S.D., Aiken, G.R., Wollheim, W.M., and Bergamaschi, B.A., 2011, Taking the pulse of snowmelt - In situ sensors reveal seasonal, event and diurnal patterns of nitrate and dissolved organic matter variability in an upland forest stream: Biogeochemistry, v. 108, no. 1, p. 183-198.

Pellerin, B.A., Stauffer, B.A., Young, D.A., Sullivan, D.J., Bricker, S.B., Walbridge, M.R., Clyde, G. A., and Shaw, D.M., 2016, Emerging tools for continuous nutrient monitoring networks-Sensors advancing science and water resources protection: Journal of the American Water Resources Association, v. 52, no. 4, p. 993-1,008.

Saleh, D., and Domagalski, J., 2015, SPARROW modeling of nitrogen sources and transport in rivers and streams of California and adjacent States, US: Journal of the American Water Resources Association, v. 51, no. 6, p. 1,487-1,507.

Saraceno, J.F., Pellerin, B.A., Downing, B.D., Boss, E., Bachand, P.A.M., and Bergamaschi, B.A., 2009, Highfrequency in situ optical measurements during a storm event-Assessing relationships between dissolved organic matter, sediment concentrations, and hydrologic processes: Journal of Geophysical Research, v. 114, no. G4.

Schlegel, B., and Domagalski, J.L., 2015, Riverine nutrient trends in the Sacramento and San Joaquin Basins, California-A comparison to State and regional water quality policies: San Francisco Estuary and Watershed Science, v. 13, no. 4, 30 p.

Schoellhamer, D.H., Mumley, T.E., and Leatherbarrow, J.E., 2007, Suspended sediment and sediment-associated contaminants in San Francisco Bay: Environmental Research, v. 105, no. 1, p. 119-131.

Senn, D.B., and Novick, E., 2014, Suisun Bay ammonium synthesis report: Richmond, California, San Francisco Estuary Institute, 155 p. plus appendixes.

Wagner, R.J., Boulger, R.W., Jr., Oblinger, C.J., and Smith, B.A., 2006, Guidelines and standard procedures for continuous water-quality monitors-Station operation, record computation, and data reporting: U.S. Geological Survey Techniques and Methods, book 1, chap. D3, 51 p. plus 8 attachments. 


\section{Appendix A. All Known High-Frequency Monitoring Stations and Water-Data Parameters Recorded, Sacramento- San Joaquin Delta, Northern California}




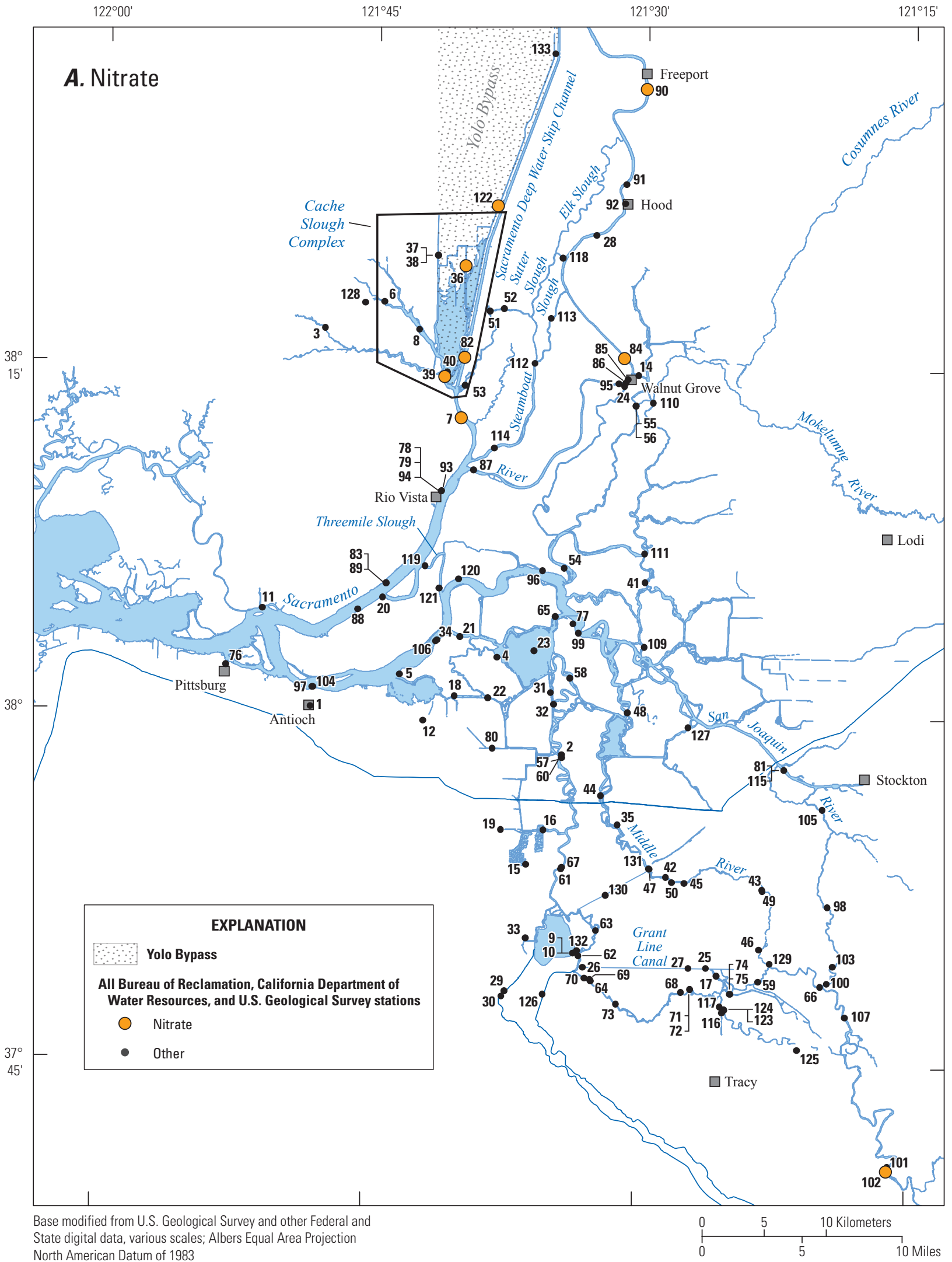

Figure A1. All known surface-water monitoring stations ever reporting any type of high-frequency monitoring data overlaid with stations where measurements are reported for $(A)$ nitrate, $(B)$ chlorophyll-a fluorescence, $(C)$ dissolved oxygen, $(D)$ turbidity, Sacramento-San Joaquin Delta, northern California. (Station details are shown in appendix table A1.) 


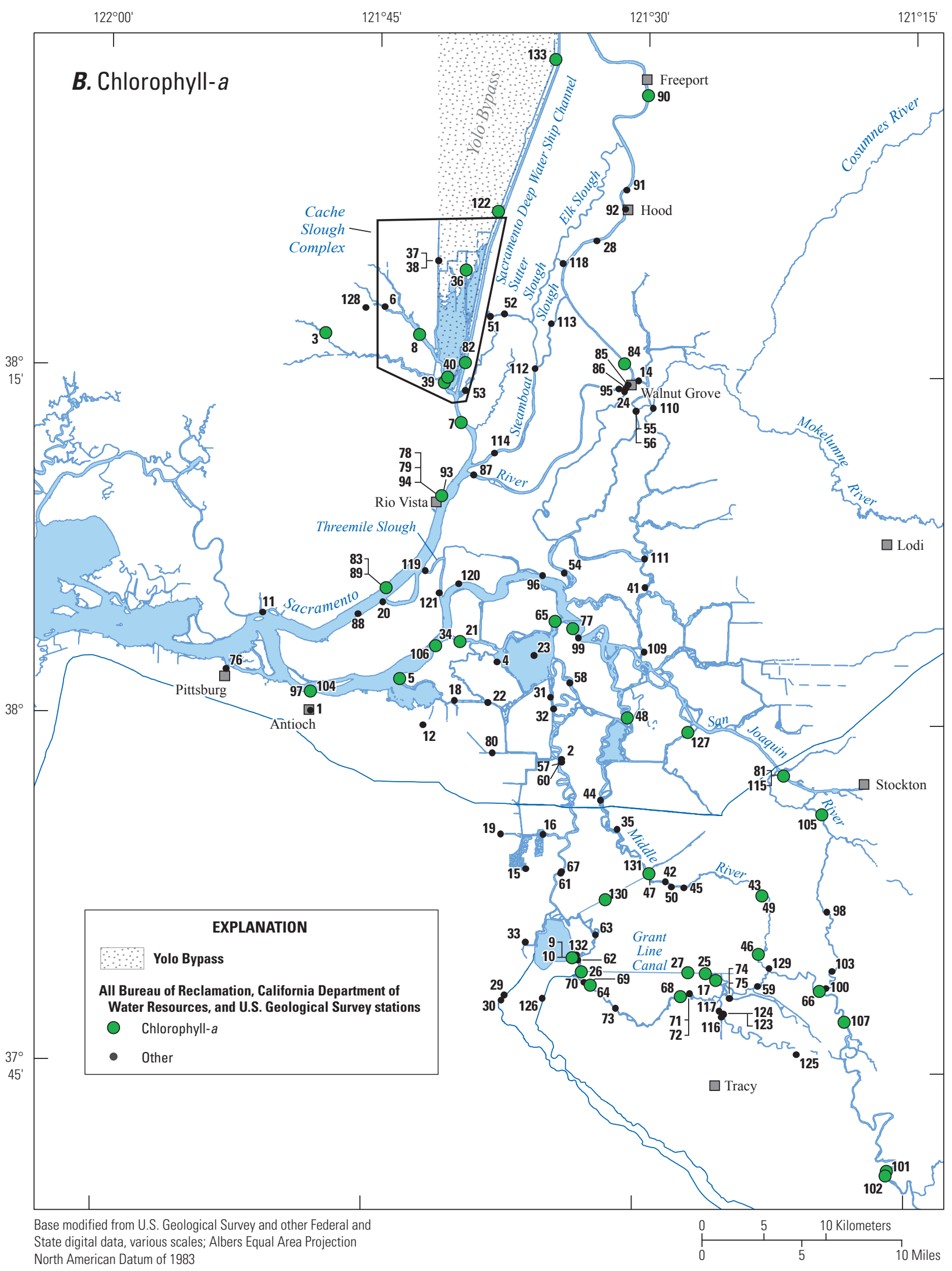

Figure A1.-Continued. 


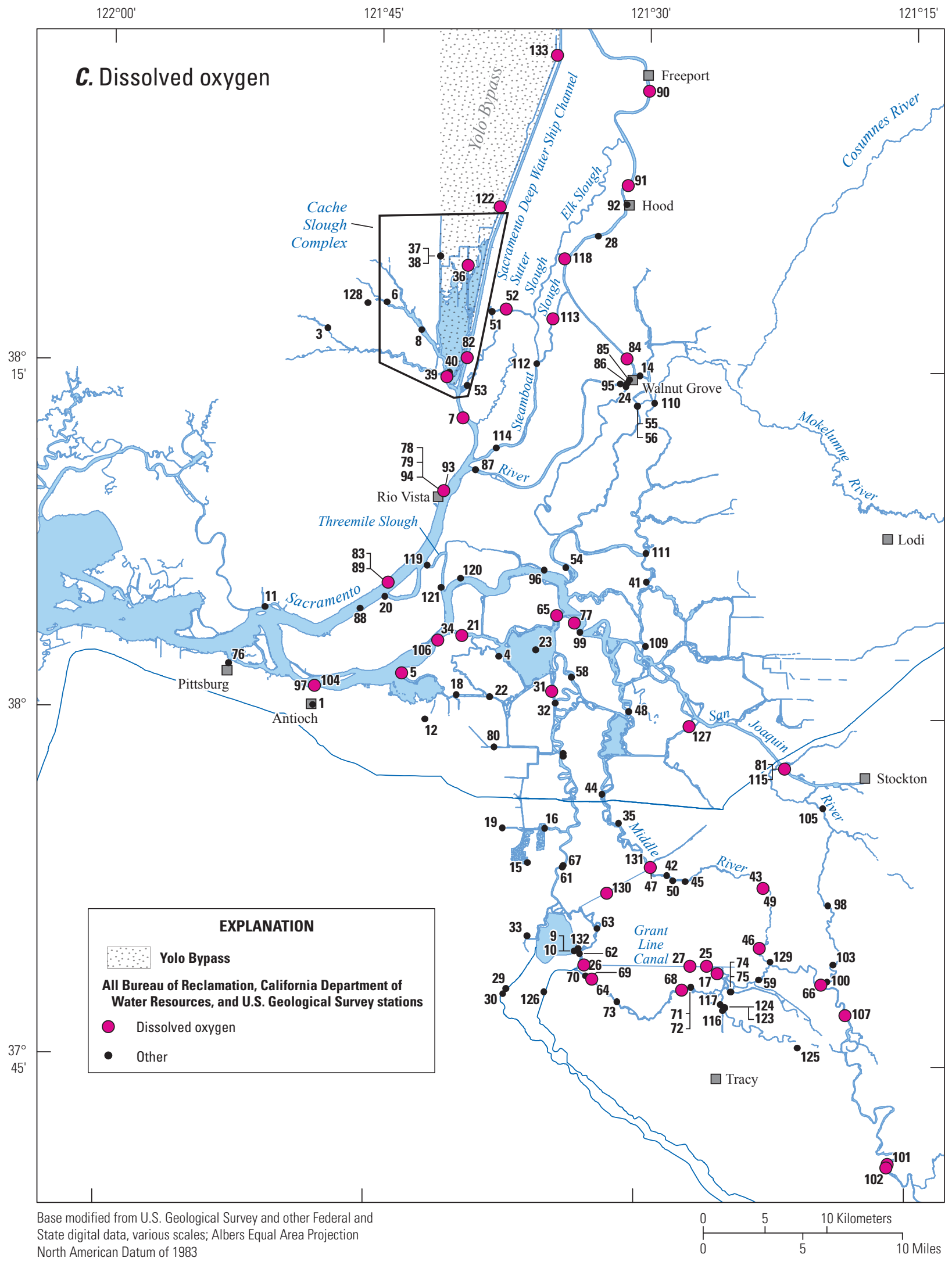

Figure A1.-Continued. 


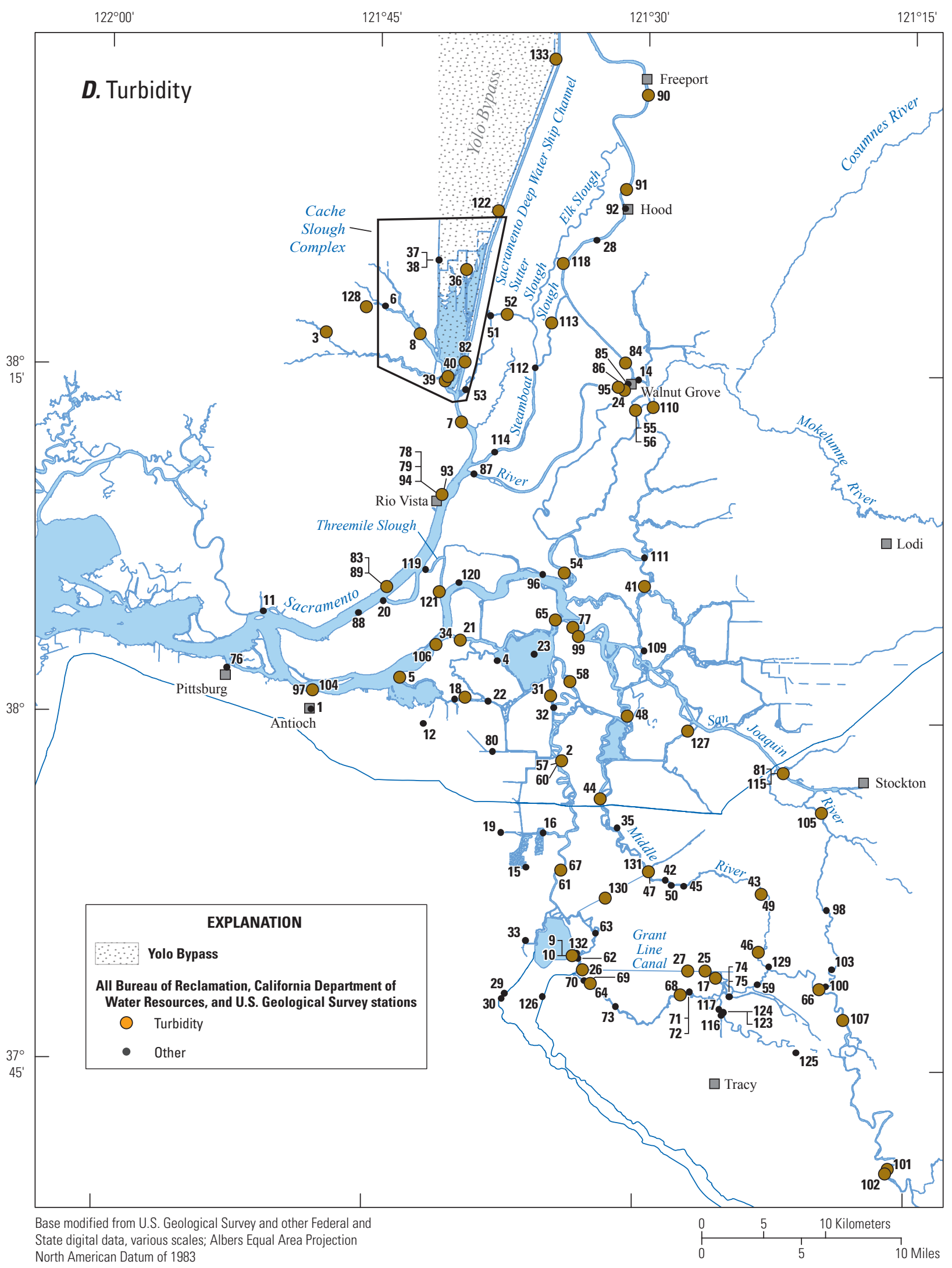

Figure A1.-Continued. 


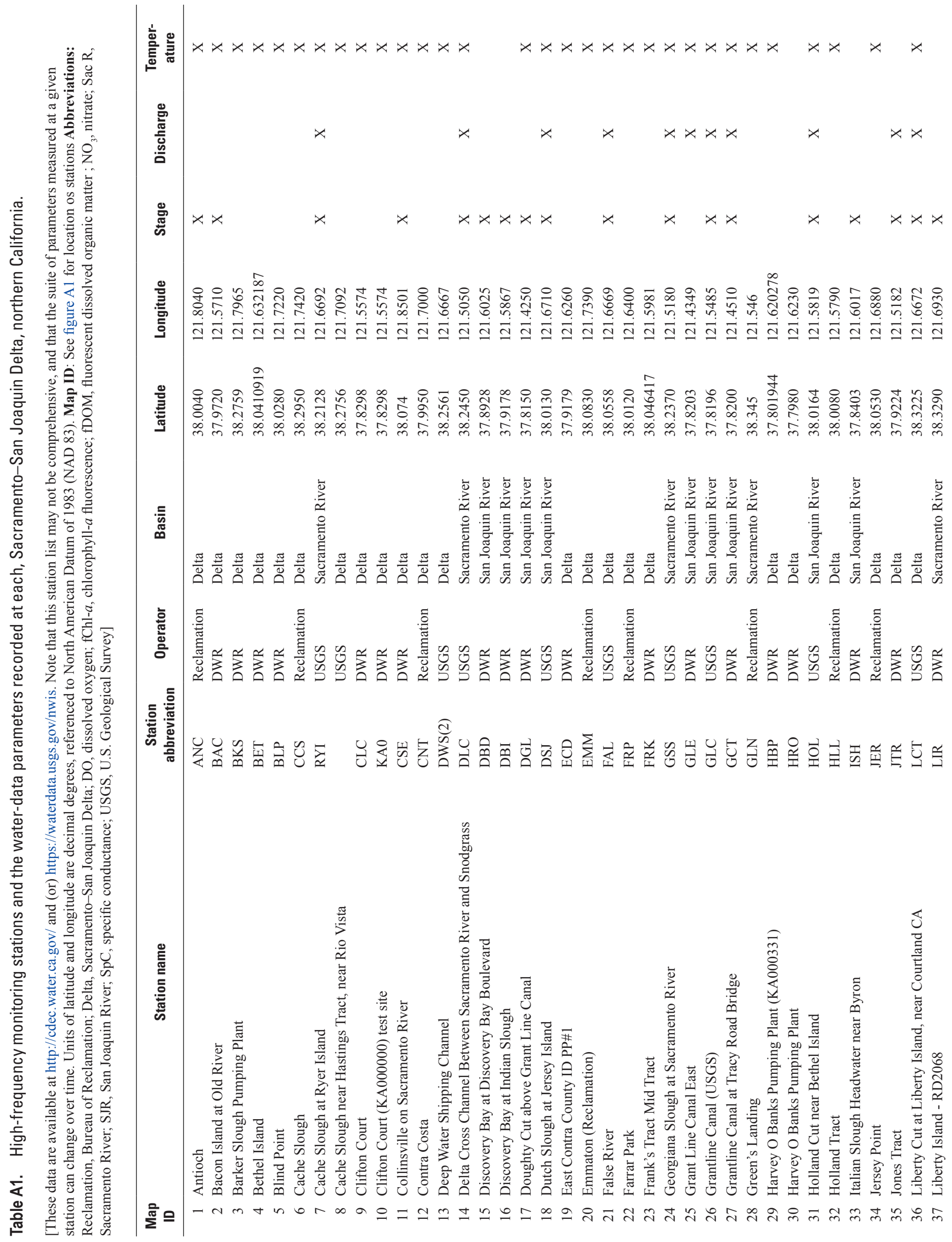




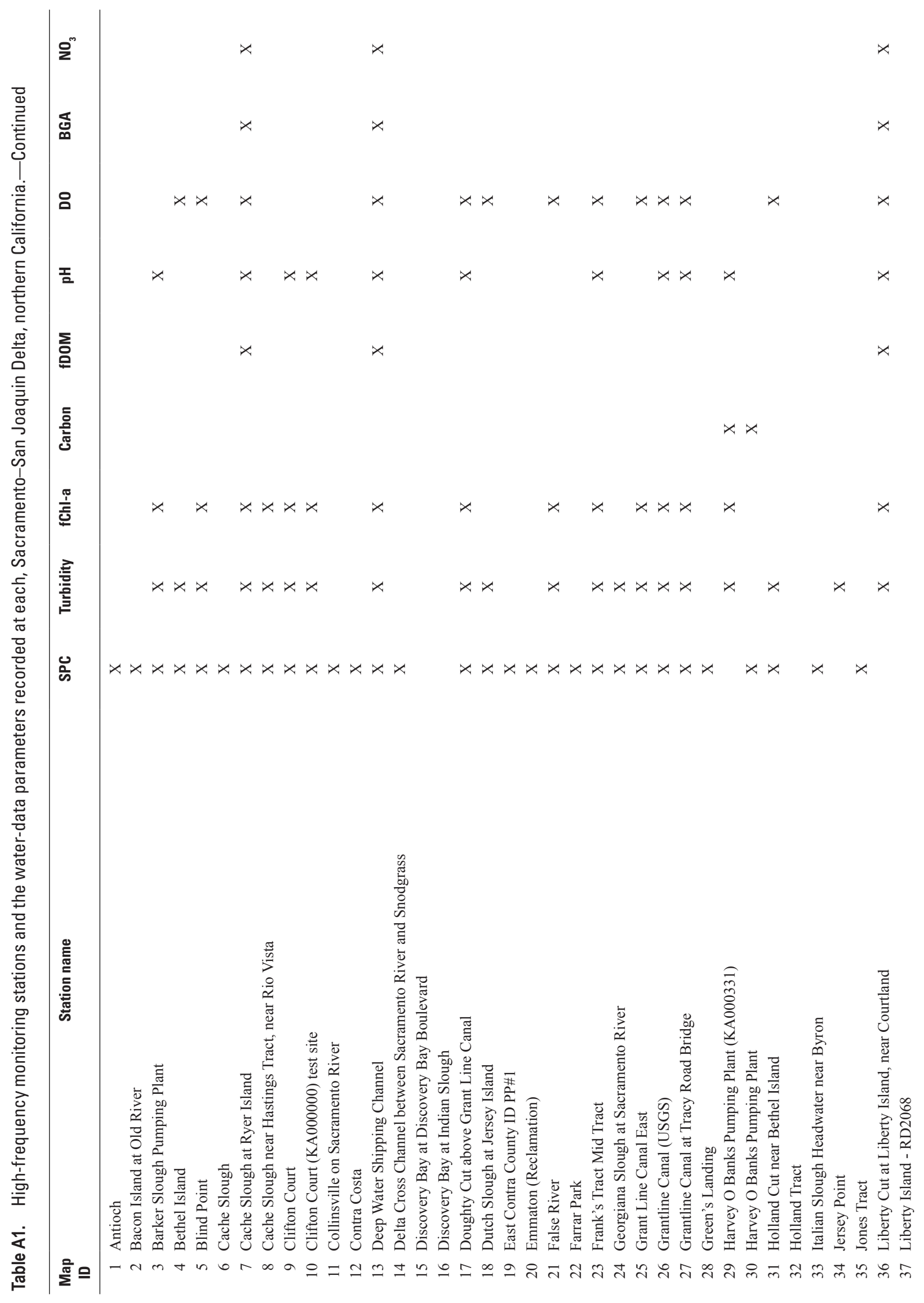




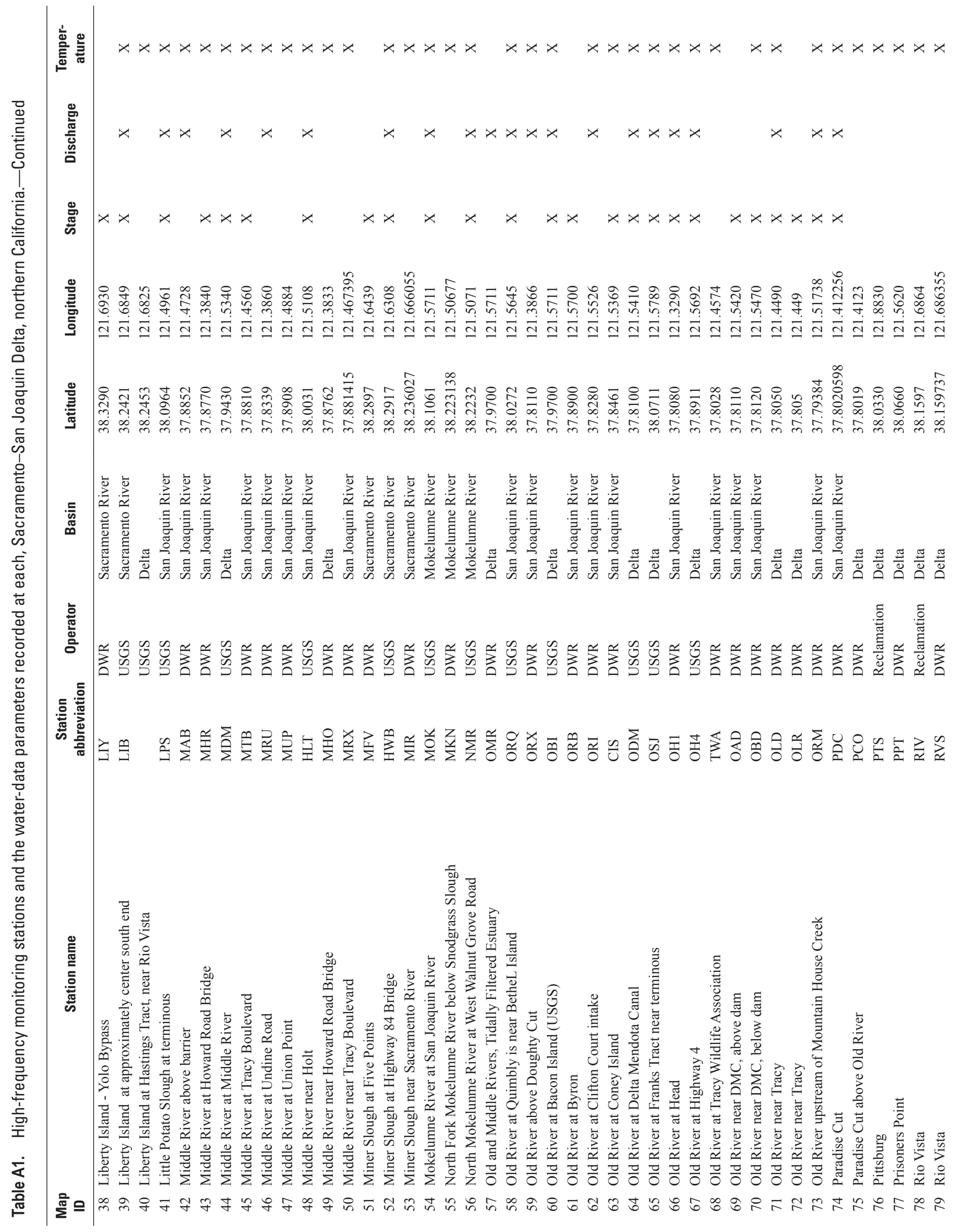




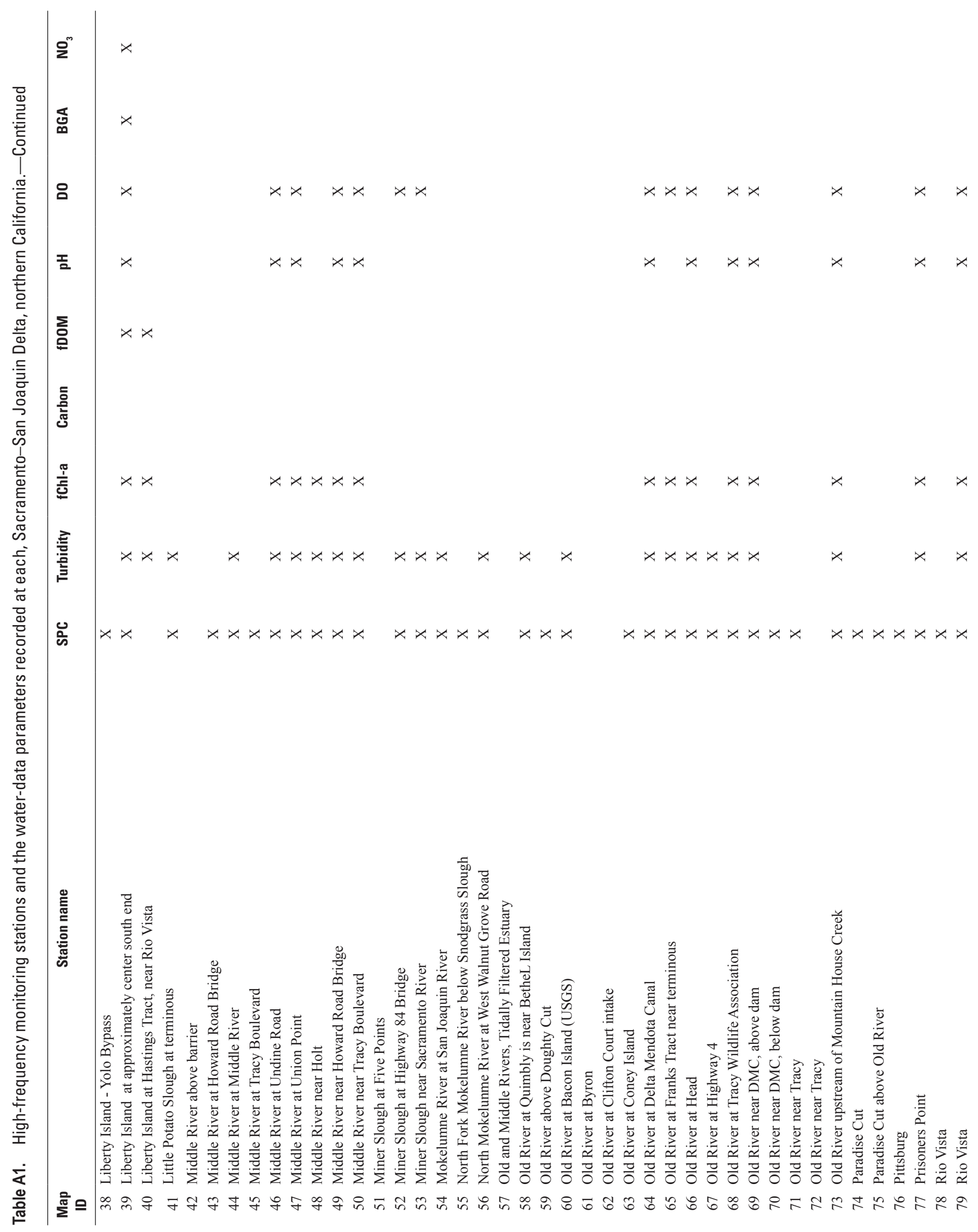




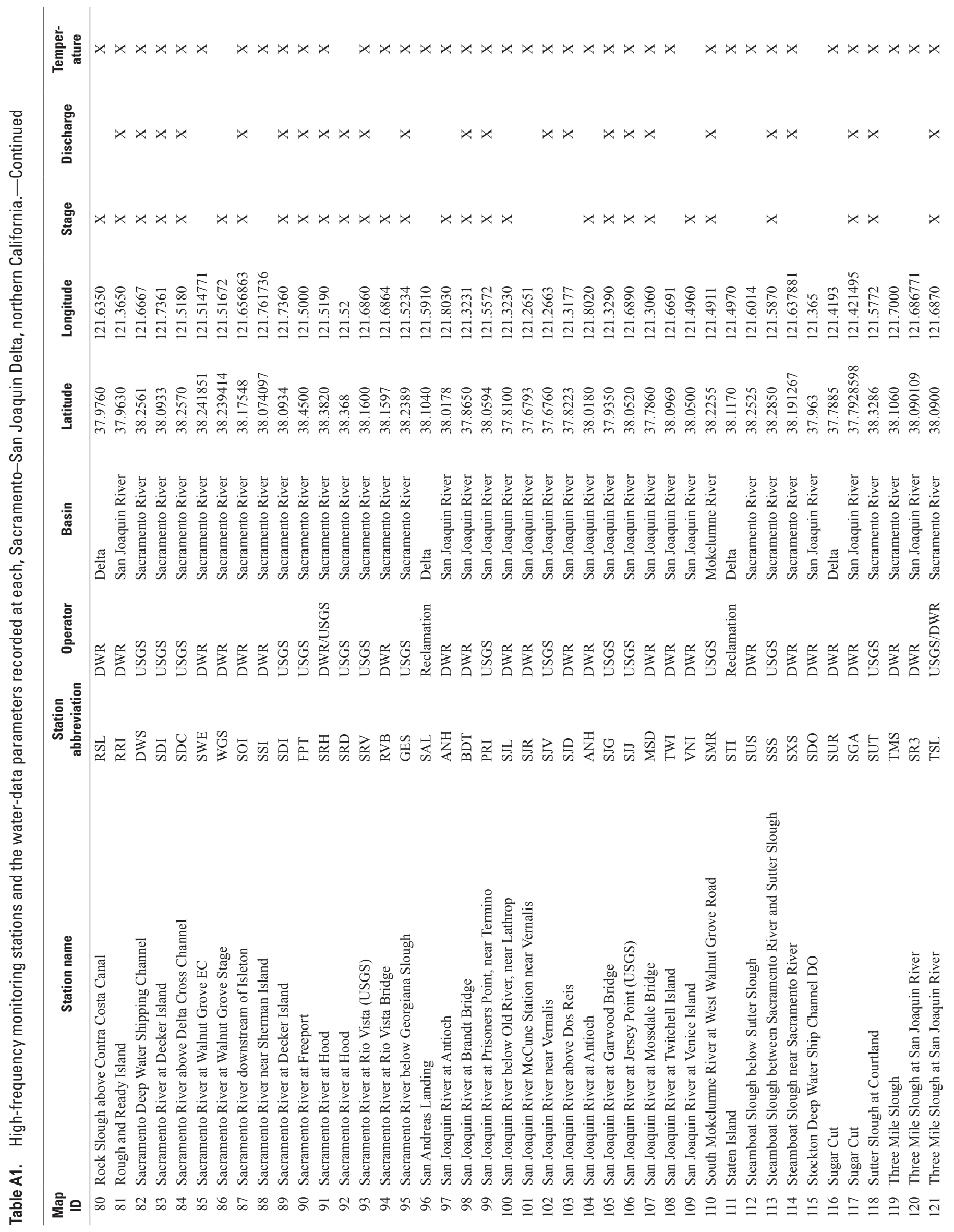




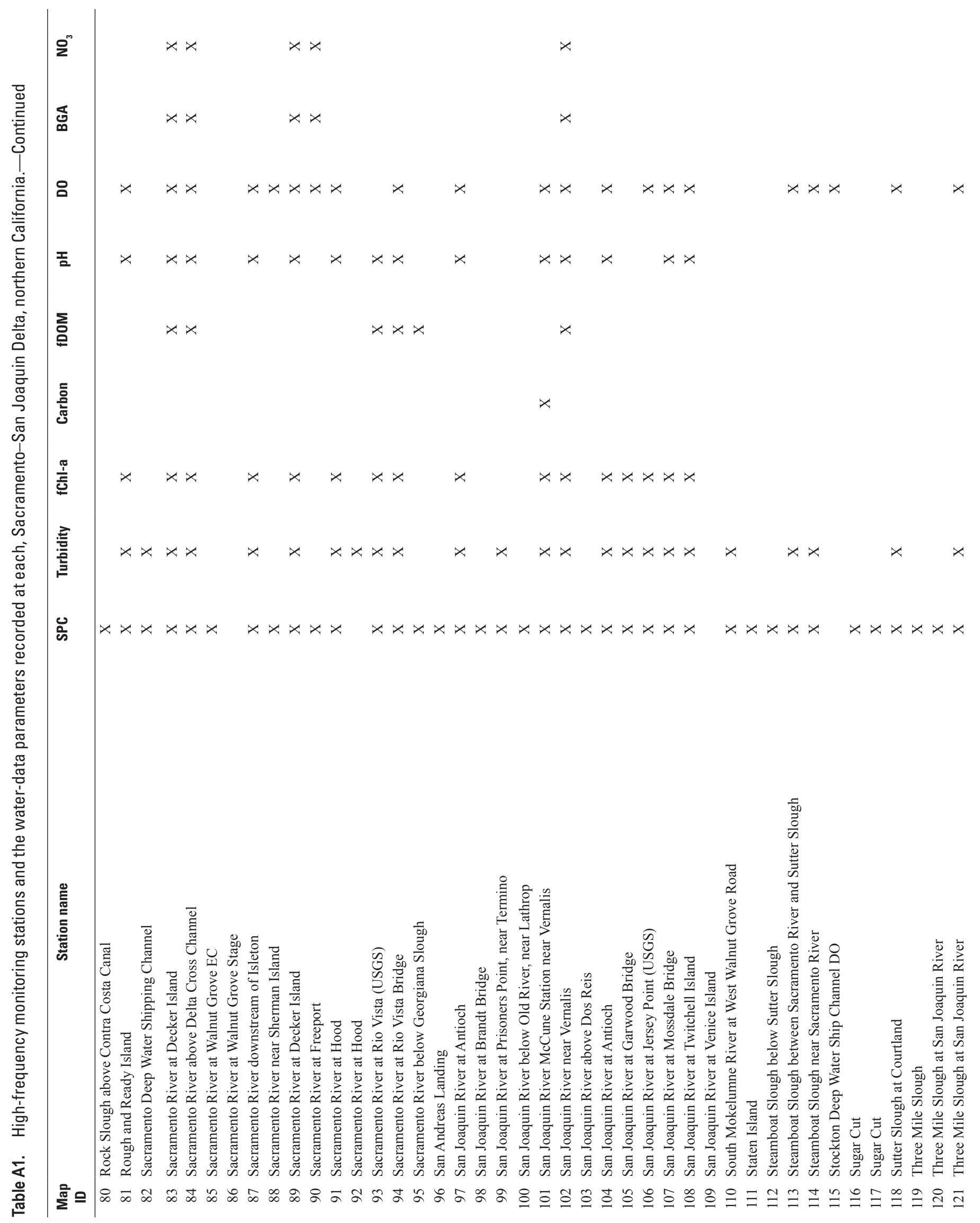




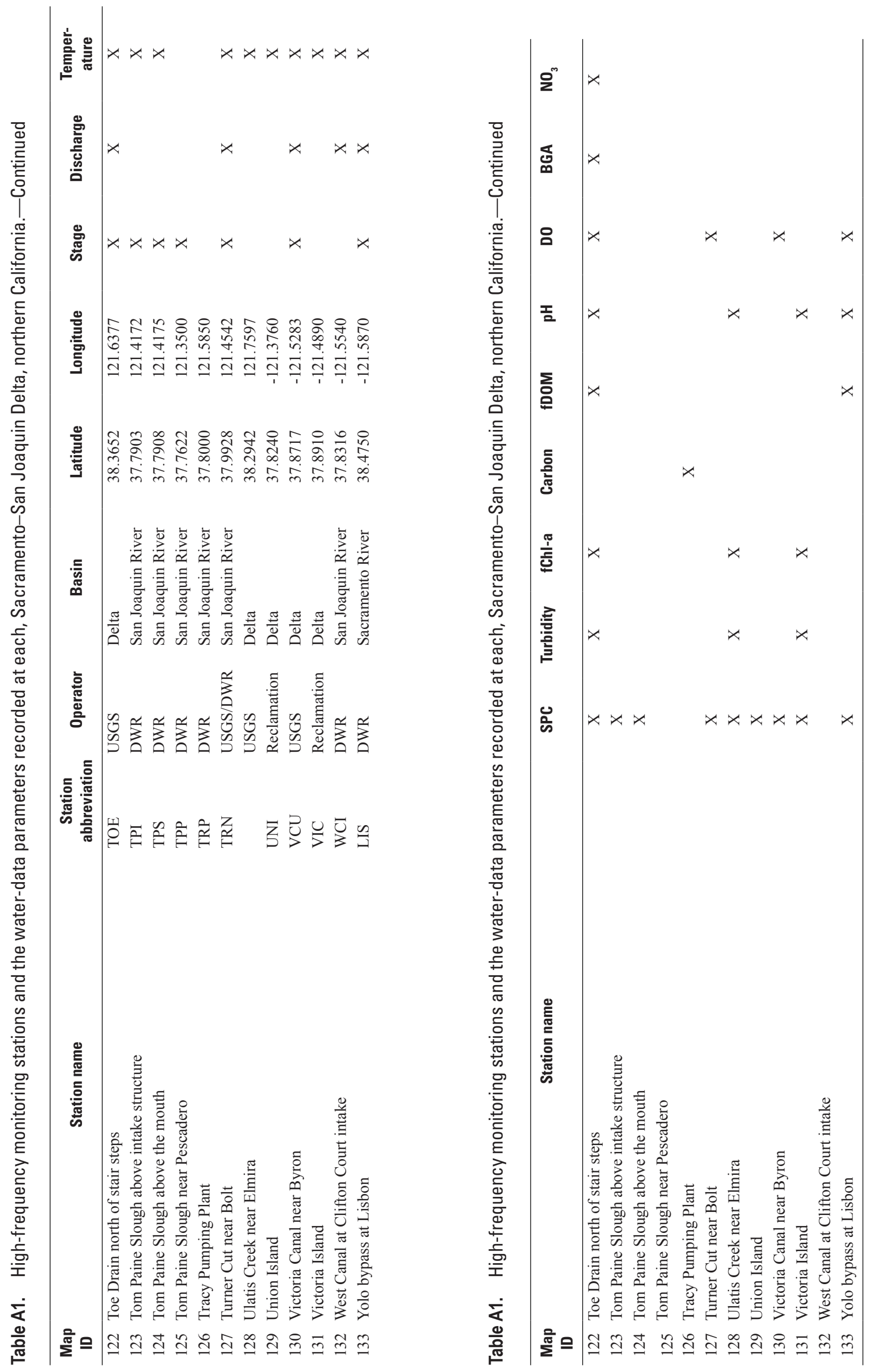


Publishing support provided by the U.S. Geological Survey Science Publishing Network, Tacoma Publishing Service Center For more information concerning the research in this report, contact the Director, California Water Science Center

U.S. Geological Survey

California State University Placer Hall

$6000 \mathrm{~J}$ Street

Sacramento, California 95819-6129

http://ca.water.usgs.gov 

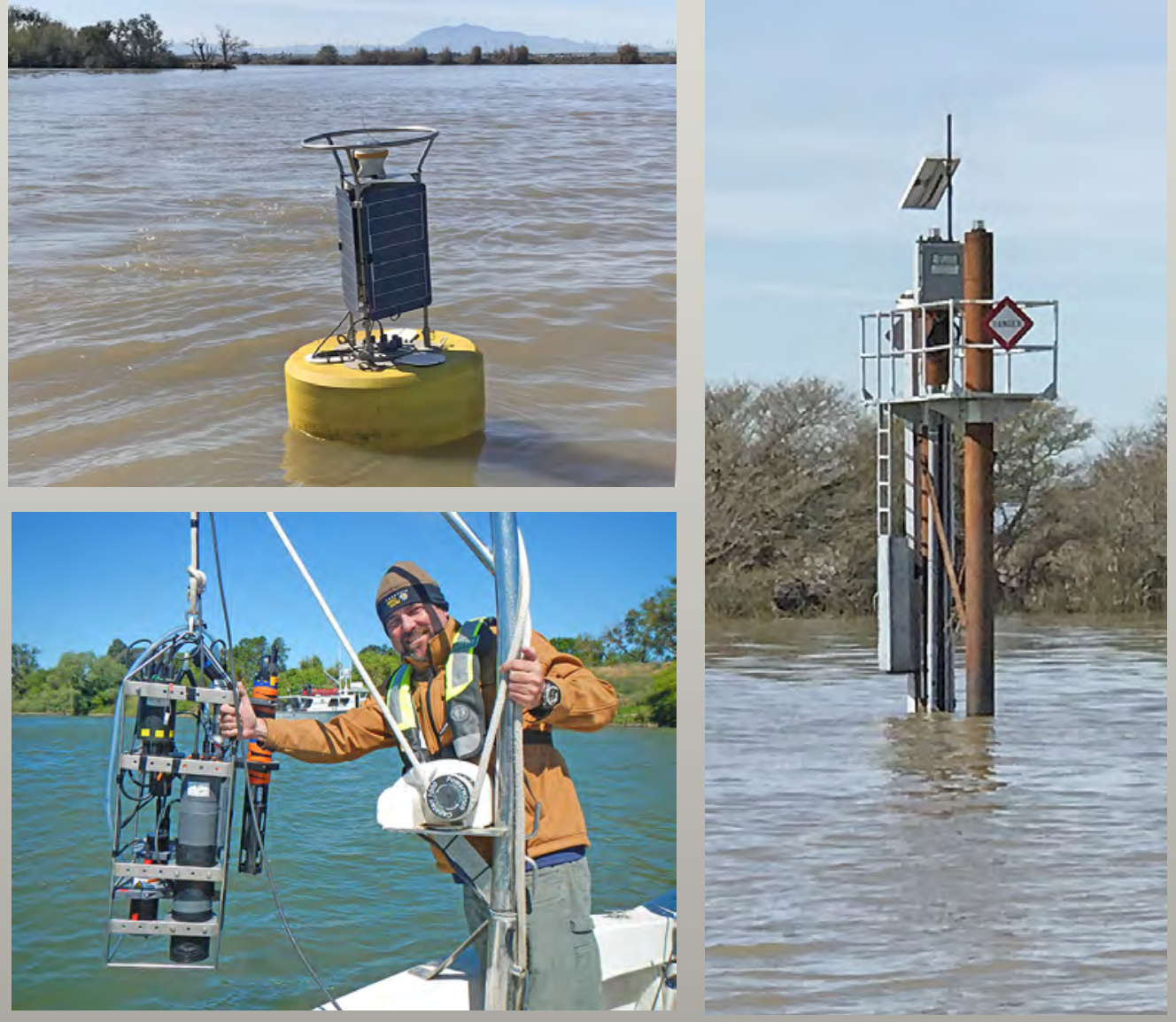

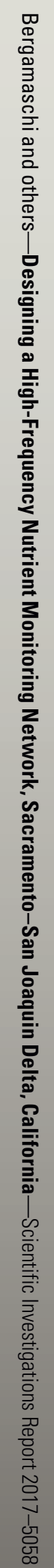

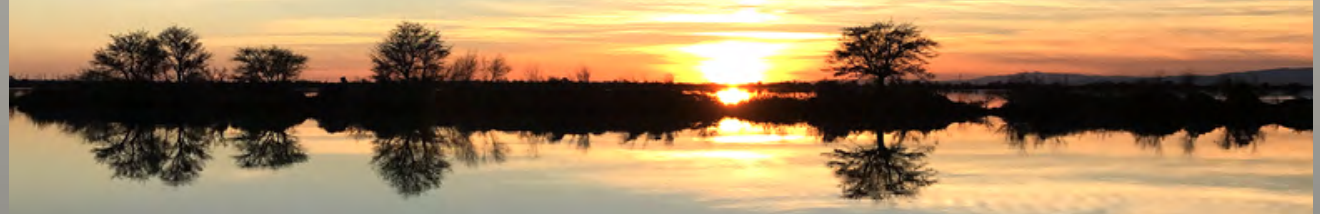

